\title{
Power Radiated from ITER DE90 014715 and CIT by Impurities
}

\author{
J. Cummings, S. A. Cohen, R. Hulse, D. E. Post, \\ M. H. Redi and J. Perkins ${ }^{\dagger}$
}

Princeton Plasma Physics Laboratory

Princeton University, Princeton, NJ 08543

\begin{abstract}
The MIST code has been used to model impurity radiation from the edge and core plasmas in ITER and CIT. A broad range of parameters have been varied, including $Z_{e f f}$ impurity species, impurity transport coefficients, and plasma temperature and density profiles, especially at the edge. For a set of these parameters representative of the baseline ITER ignition scenario, it is seen that impurity radiation, which is produced in roughly equal amounts by the edge and core regions, can make a major improvement in divertor operation without compromising core energy confinement. Scalings of impurity radiation with atomic number and. machine size are also discussed.
\end{abstract}

†Permanent Address: Lawrence Livermore National Laboratory, Livermore, CA 94550. 


\section{Introduction}

Though the presence of impurities in fusion plasmas is generally considered detrimental because of adverse effects on global energy confinement and fuel dilution, impurities can play a key positive role by radiating power from the plasma edge region, $0.9<\mathrm{r} / \mathrm{a}<1.0$, and the scrape-off layer (SOL), $\mathrm{r} / \mathrm{a}>1.0 .1$ For example, the ITER ${ }^{2}$ design specifies power deposition in the plasma of about 200 MW by alpha particles and up to $150 \mathrm{MW}$ by auxiliary heating, burn-control, current-drive or MHD stabilization systems. This power must be exhausted from the plasma, either by higily localized charged-particle conduction to the divertor plates or by more widely distributed radiation and charge exchange to the tokamak walls and divertor plates. Computer simulations 3,4 of the operating parameters for divertors show a high sensitivity of the peak power load, the peak elect:on temperature at the sheath, and the divertor erosion rate to the extausted power, particularly that in the ion conduction channel. Two-dimensional plasma edge simulations of the present ITER design typically show that less than $100 \mathrm{MW}$ of the power deposited in the plasma must reach the double-null divertor plates (via conduction) to avoid intolerably high power loads 5 and erosion. 6

Therefore, consideration must be given to exhausting energy by radiation. Radiation from the core of the plasma, whether by bremsstrahlung, line radiation or synchrotron radiation, must be minimized because of the degradation of central energy confinement time. But a large fraction of line radiation from impurities in plasmas as hot and as large as ITER or CIT may be expected to originate in the edge and SOL, where the lower ionization states predominate. The detailed effects of 
various plasma parameters on the fraction of impurity-radiated power which originates from the edge region are important.

To assess whether the impurity concentrations expected (and tolerable) in ITER are adequate to cause greater than $100 \mathrm{MW}$ of radiated power from the edge, we have simulated impurity radiation processes using a $1-\mathrm{d}$ multi-species impurity transport code.7 Two generic ITER plasma conditions were studied: high density and low density. 8 These conditions are representative of ignited and non-inductive current-drive operation, respectively. Particle transport coefficients spanning the expected range for $\operatorname{ITER}^{9,10}$ were used. These include diffusivities independent of radius, as well as those linearly increasing with $\mathrm{r} / \mathrm{a}$. Impurity convection (inward) was also varied. A few simulations were made of necclassical-type impurity transport commonly associated with the notion of an impurity ion density profile strongly peaked on axis. For a standard set of diffusion and convection coefficients, separate studies of radiated power versus machine size and edge plasma temperature were made. A similar, but more limited, study exploring impurity radiation from CIT was conducted as well.

We find that, in the ITER low density case, an impurity mix corresponding to $Z_{\text {eff }} \sim 2.26$ can radiate $-50 \mathrm{MW}$. High density operation, typical of ignition scenarios in ITER, increases the radiation to $-250 \mathrm{MW}$. In both cases, about half of the radiation comes from the small amount of Fe $(0.05 \%)$ specified. For slow inward pinch velocities, a sizable fraction, typically $50 \%$, of the radiation from each element (except helium) does come from the edge. Faster pinch velocities yield greatly reduced edge radiation. Edge temperatures below $\sim 50 \mathrm{eV}$ increase the line radiation of carbon dramatically. CIT, with a $Z_{\text {eff }}$ of 1.65 , radiates $-25 \mathrm{MW}$ in our simulations 
(as compared to $100 \mathrm{MW}$ of expected alpha heating power), with roughly $30-40 \%$ of that coming from the edge region.

The MIST simulations do not include a $2-\mathrm{d}$ model of the SOL and divertor regions. Because of the intense recycling, large impurity release rates and low plasma temperatures expected in these regions, further increases in impurity radiation may be expected, as described in interim ITER reports, e.g., ref. 11. These effects undoubtedly will have an impact on divertor operating conditions and plasma stability, particularly near the density limit. 12,13,14 


\section{Methods and Inputs}

Simulations of the radiation of various impurities were performed using the MIST (Multi-Ionic Species Transport) code, ${ }^{7}$ which models radial transport of impurity ions in a plasma with a cylindrical, axisymmetric geometry. The types of impurity radiation processes included in MIST are recombination (including dielectronic), bremsstrahlung, and bound-bound transitions. Charge exchange and synchrotron radiation are not included. Although rate coefficients for the ionization processes have been updated, 15 no new estimation of the associated accuracy of the radiated power has been made.

The fiuxes of the various impurity ionic species are determined by the set of equations

$$
\begin{aligned}
& \Gamma_{j}=-D^{*} \nabla n_{j}+v^{*} n_{j} \text { and } \\
& \partial n_{j} / \partial t=-\nabla \cdot \Gamma_{j}+s_{j}
\end{aligned}
$$

where $\Gamma_{j}$ and $n_{j}$ are the flux and density of the $j^{\text {th }}$ ionic charge state of the impurity, respectively, and $s_{j}$ is the net source and sink caused by ionization and recombination. The diffusion coefficient for all charge states is

$$
D(r)=D_{A C}+D_{A R}{ }^{*}(r / a) \text { DAREXP, }
$$


where $a$ is the separatrix radius and also the radial position of the impurity source (see Fig. 1). $D_{A C}, D_{A R}$ and $D_{A R E X P}$ are input parameters. For the ITER simulations, they were varied in the following matrix:

$$
\begin{aligned}
& D_{A C}=0.1,0.3,1.0,3.0 \mathrm{~m}^{2} / \mathrm{s} \\
& D_{A R}=0,2 * D_{A C} \\
& D_{A R E X P}=1.0 .
\end{aligned}
$$

A diffusion coefficient of $-0.4 \mathrm{~m}^{2} / \mathrm{s}$ is expected for ITER. 9 For the CIT runs, a constant diffusion coefficient of $0.1,0.3$ or $1.0 \mathrm{~m}^{2} / \mathrm{s}$ was used $\left(D_{A R}=0\right)$.

The "pinch" velocity is described by the equation

$$
\mathrm{v}(\mathrm{r})=\mathrm{C}_{\mathrm{vr}} *\left[-2^{*} \mathrm{D}(\mathrm{r})^{*} \mathrm{r} / \mathrm{a}^{2}\right]
$$

where $C_{v r}$ is an input parameter. $C_{v r}$ was set to either 0 or 0.1 for most MER cases, although some highly convective runs were made, with $C_{\mathrm{vr}}$ ranging from 1 to 10 . CIr simulations were made with $\mathrm{C}_{\mathrm{yr}}$ set to 0.1 or 1 . Experiments show a broad range of $C_{\mathrm{vr}}$ values, with the range $0-1$ being typical, 16 though values as high as 20 have been observed. 17 Generally speaking, quiescent $H$-mode discharges have a large $C_{v x}$, while L-modes and $\mathrm{H}$-modes with grassy ELMS have a low $\mathrm{C}_{\mathrm{vr}}$. Neoclassical transport theory results in a value for $C_{v r}$ which is roughly equal to $Z$, the ionic charge of the impurity, 18 Our reference case for the ITER machine size and edge temperature studies was $D(r)=0.3 \mathrm{~m}^{2} / \mathrm{s}$ and $v(r)=0 \mathrm{~m} / \mathrm{s}$, and our standard transport 
coefficients for CTT were $D(r)=0.3 \mathrm{~m}^{2} / \mathrm{s}$ and $v(r)=-0.2^{*} D(r)^{*} r / \alpha^{2}$.

The radial temperature and electron density profiles of $\operatorname{ITER}^{9}$ required as input for MIST were provided by the BALDUR code. 19 The profiles can be generically described by the equations

$$
\begin{aligned}
& T_{\alpha}(r)=\left[T_{\alpha}(0)-T_{\alpha}(a)\right]^{*}\left[1-(r / a)^{2}\right]^{\alpha}+T_{\alpha}(a) \text { and } \\
& n_{e}(r)=\left[n_{e}(0)-n_{e}(a)\right]^{*}\left[1-(r / a)^{2}\right]^{\mu}+n_{e}(a)
\end{aligned}
$$

where $\alpha$ represents the species (electrons or ions) and $\gamma_{\alpha}$ and $\mu$ determine the profiles' peakedness. These profiles were calculated using a simple model of impurity radiation that assumed about $30 \%$ of the power being lost as radiation from the edge region. The ion (both hydrogenic and impurity) density profiles are determined by transport equilibrium of the impurity ions and quasi-neutrality of the plasma. Two different BALDUR cases were selected: a high density (ignition) case and a low density (non-inductive current-drive) case. For the high density case, the ITER physics phase configuration (pre-August 1989) was chosen. The low density case was chosen to simulate current-drive in the ITER technology phase configuration. (The geometric size of ITER has since grown about 3\% in major radius. The scaling of impurity radiation with changes in $\mathbf{R}$ and $a$ is discussed later.) The density profiles of both scenarios are flat, as is typical of edge-fuelled H-mode plasmas. Since the plasma cross section in MIST is circular, the minor radius is chosen to give the correct plasma volume. The parameters describing the two ITER cases are shown in the following table: 
Table 1. ITER Parameters

\begin{tabular}{|c|c|c|}
\hline $\begin{array}{l}\text { Parar.eter } \\
R \\
\mathbf{R} \\
\mathrm{V} \\
\mathrm{T}_{\mathrm{e}}(0) \\
\mathrm{T}_{\mathrm{e}}(\mathrm{a}) \\
\left\langle\mathrm{T}_{\mathrm{e}}\right\rangle\end{array}$ & $\begin{array}{l}\text { High density } \\
5.8 \mathrm{~m} \\
3.18 \mathrm{~m} \\
1160 \mathrm{~m}^{3} \\
25 \mathrm{keV} \\
100 \mathrm{eV} \\
10 \mathrm{keV}\end{array}$ & $\begin{array}{l}\text { Low density } \\
5.5 \mathrm{~m} \\
2.72 \mathrm{~m} \\
800 \mathrm{~m}^{3} \\
50 \mathrm{keV} \\
200 \mathrm{eV} \\
20 \mathrm{keV}\end{array}$ \\
\hline $\begin{array}{l}\gamma_{\mathbf{e}} \\
\mathrm{T}_{\mathbf{i}}(0) \\
\mathrm{T}_{\mathbf{i}}(\mathrm{a}) \\
\left\langle\mathrm{T}_{\mathbf{i}}\right\rangle\end{array}$ & $\begin{array}{l}1.5 \\
30 \mathrm{keV} \\
100 \mathrm{eV} \\
12 \mathrm{keV}\end{array}$ & $\begin{array}{l}1.5 \\
70 \mathrm{keV} \\
200 \mathrm{eV} \\
30 \mathrm{keV}\end{array}$ \\
\hline $\begin{array}{l}x_{i} \\
n_{e}(0) \\
n_{e}(a) \\
<n_{e}>\end{array}$ & $\begin{array}{l}1.5 \\
2.09 \mathrm{e} 14 \mathrm{~cm}^{-3} \\
4.2 \mathrm{e} 13 \mathrm{~cm}^{-3} \\
1.4 \mathrm{e} 14 \mathrm{~cm}^{-3}\end{array}$ & $\begin{array}{l}1.34 \\
1.04 \mathrm{e}^{14} \mathrm{~cm}^{-3} \\
2.1 \mathrm{e} 13 \mathrm{~cm}^{-3} \\
7.0 \mathrm{e} 13 \mathrm{~cm}^{-3}\end{array}$ \\
\hline $\begin{array}{l}\mu \\
\text { B } \\
q(a)\end{array}$ & $\begin{array}{l}0.7 \\
5.0 \mathrm{~T} \\
3.2\end{array}$ & $\begin{array}{l}0.7 \\
5.3 \mathrm{~T} \\
3.1\end{array}$ \\
\hline
\end{tabular}

There were two different plasma scenarios for CIT as well: normal H-mode confinement and a peaked profile case corresponding to pellet injection. 20 In either type of run, $R=214 \mathrm{~cm}, a=93 \mathrm{~cm}, B=11 \mathrm{~T}$ and $\mathrm{g}(\mathrm{a})=3.2$ were used as the standard machine parameters, and $T_{i}=T_{e}$ was assumed. The temperature profile parameters were varied in the following matrix:

$$
\begin{aligned}
& T_{e}(0)=15,20,25 \mathrm{keV} \text { and } \\
& T_{e}(a)=20,100,300 \mathrm{eV} .
\end{aligned}
$$

The density profiles of the two CIT scenarios are described by the values listed in Table 2. 
Table 2. CIT Parameters

$\begin{array}{lll}\text { Parameter } & \text { H-Mode Confinement } & \text { Pollet Injection } \\ & 7.5 \mathrm{e} 14 \mathrm{~cm}_{e}^{-3}(0) & 1.6 \mathrm{e} 15 \mathrm{~cm}^{-3} \\ n_{e}(a) & 1.5 \mathrm{e} 14 \mathrm{~cm}^{-3} & 9.5 \mathrm{e}^{-3} \mathrm{~cm}^{-3} \\ \left\langle n_{e}\right\rangle & 5.25 \mathrm{e} 14 \mathrm{~cm}^{-3} & 5.25 \mathrm{e} 14 \mathrm{~cm}^{-3} \\ \mu & 0.6 & 2.5\end{array}$

In both ITER cases, the 1/e decay length of the density in the SOL was fixed at $\lambda_{\text {ne }}=10 \mathrm{~cm}$ for the electrons and $\lambda_{\mathrm{ni}}=15 \mathrm{~cm}$ for the impurity ions. The temperature decay length (see Fig. 1) was much shorter: $\lambda_{\mathrm{T} \alpha}=0.24$ for the low density case and $\lambda_{\mathrm{T} \alpha}=0.36 \mathrm{~cm}$ for the high density case. These values are consistent with predictions from thodeling. 5 Below $T_{e}=7 \mathrm{eV}$ the carbon radiation rate drops precipitously. 21 This results in a very narrow region of line radiation in the scrape-off layer. For CIT cases, the SOL parameters were $\lambda_{\mathrm{nl}}=3 \mathrm{~cm}, \lambda_{\mathrm{ne}}=3 \mathrm{~cm}$ and $\lambda_{\mathrm{Ta}}=0.5 \mathrm{~cm}$.

A finer radial mesh was used in the outer plasma region (roughly $r / a>0.8$, where line radiation from the impurities is dominant) than in the plasma core. Scans over mesh size, described later, showed that our element-dependent choices were adequate to discriminate individual ionization charge states near the plasma edge, i.e., down to the +4 state of Fe.

Seven different impurities were studied for ITER: helium, carbon, oxygen, aluminum, iron, molybdenum and iungsten. In 1989, $\mathrm{Al}, \mathrm{Mo}$ and $\mathrm{W}$ were not planned for use in ITER; we chose to include them in this study because of potential future applications. ( $W$ is now specified as the first option for the Technolgy Phase divertor plate material.) The 1988 ITER $\mathrm{Z}_{\text {eff }}$ specification was 2.26, comprised of the 
elements listed in Table 3.

Table 3.1988 ITER. $Z_{\text {eff-Specification }}$

$\begin{array}{lll}\text { Element } & \text { Conc }\left(n_{\mathrm{f}} / n_{\mathrm{Q}}\right) & Z_{\text {eff }} \\ \mathrm{D} / \mathrm{T} & 0.66 & 0.66 \\ \mathrm{He} & 0.10 & 0.40 \\ \mathrm{C} & 0.015 & 0.54 \\ \mathrm{O} & 0.005 & 0.32 \\ \mathrm{Fe} & 0.0005 & 0.34\end{array}$

The present impurity specification for ITER, described in Sect. IV, is density dependent, with $Z_{\text {eff }}$ ranging from about 1.7 in the high density case to 2.1 in the low density case.

The elements $\mathrm{He}, \mathrm{C}$ and Fe were included in the CIT studies. However, the CIT design calls for a $Z_{\text {eff }}$ of 1.65 , composed of $D / T$ and $2.17 \% \mathrm{C}$ only. But even in the short pulses of CTT, significant He buildup may occur, as has been studied in earlier BALDUR simulations. 22 Radiation enhancement via Fe or Ne injection, examples of non-recycling and recycling impurities, respectively, is not currently planned for CTT.

The impurity radiation calculations are done without regard to concentrations because the plasma profiles are fixed in the MIST code. All MIST code simulations were run to steady state. Parallel losses and losses to the wall, both in the SOL, are allowed by the code, and all losses are replaced by ax. Influx of singly-ionized impurities from a source at $r=a$ which is adequate to maintain the prescribed impurity concentration. 


\section{Results}

\subsection{ITER}

Figures $2 \mathrm{a}$ and $2 \mathrm{~b}$ show an example of the steady-state radial profiles of individual charge state and to'a! impurity ion distributions for iron in ITER. In this simulation, the transport coufficients were $C_{\mathrm{Vx}}=0.1$ and $D(r)=0.3 \mathrm{~m}^{2} / \mathrm{s}$. The density profile is only slightly peaked, since tize impurity source is at the edge and the inward pinch is small. As exnected, the lower charge states show up only in the cooier edge region, the most abundant ones being the He-like (1+24) and Ne-like $(+16)$ states. Figures $2 \mathrm{c}$ and $\mathrm{zd}$ show the effect of altering the mesh size on total radiaied power as well as that in the high resolution area only. In all nuns, the total number of mesh points is fixed. For most runs, a mesh size of $0.9 \mathrm{~mm}$ was used for $C$, and for Fe a value of $1.8 \mathrm{~cm}$ was adequate.

Figures $3 i t$ and $3 \mathrm{~b}$ show the sadiated power for $\mathrm{He}, \mathrm{C}, \mathrm{Al}, \mathrm{Fe}, \mathrm{Mo}$ and $\mathrm{W}$ as a function of difiusion coefficient and inward pinch for the two densities. The volume-averaged impurity concentration was $1 \%$. (The radiation from $\mathrm{O}$, which is not plotted, is rearly a factor of 2 times that of $C$ and behaves similarly as a function of diffusivity.) The general trends are described below:

1. The higher $Z$ impurities radiate more. As shown in Fig. 4 , the cotal radiated power is proportional to $Z^{3}$, confirming, at higher electron temperature and for non-coronal equilibrium, the $Z^{3}$ dependence of impurity radiation 
implied in Fermi's golden rule and noted earlier by Ashby and Hughes for coronal equilibrium. 14

2. Radiation is greater at higher $D$ (when $D(r)=$ constant), mainly because a stronger impurity influx is needed to balance the more rapid loss rate. A lesser reason is that lower ionization states, which have more bound electrons and are better radiators, are transported into hotter parts of the plasma.

3. The radiation level intercepts the $D=0$ axis at the coronal equilibrium value. A few extremely low $D$ cases with carbon and iron impurities were run to check the MIST code against coronal equilibrium models. $21 \mathrm{C}$ radiation levels off when $D<.01 \mathrm{~m}^{2} / \mathrm{s}$ at about $2 / 3$ of its value at $D=0.3 \mathrm{~m}^{2} / \mathrm{s}$, while Fe radiation is constant for $D<0.1 \mathrm{~m}^{2} / \mathrm{s}$. The values obtained are within $10 \%$ of the analytic evaluation of reference 21 's coronal equilibrium radiation rates when those models for collisional ionization were used. The newer rates, ${ }^{15}$ employed in all the studies reported here, give $50 \%$ less radiated power for $\mathrm{C}$ but $10 \%$ more for $\mathrm{Fe}$ than the analytic calculation in coronal equilibrium.

4. Radiation when $D(r)$ monotonically increases with radius is greater than when $D(r)=$ constant for the same reasons as in 2. Specifically, $D(a)$ is three times bigger in the monotonically increasing case, which means the impurity influx from the edge source will be stronger.

5. The weak inward pinch slightly lowers the radiated power, since fewer impurities are present near the edge.

6. The power radiated at low density is less than that of the high density case, 
mostly because the numbers of both impurity ions and electrons are fewer.

An additional consideration with respect to the sixth trend is that the smaller plasma volume of the low density case will obviously contribute to the lower radiation yield as well. This motivates the study of how radiated power levels will scale with major and minor radius. In order to evaluate the dependence of core and edge radiation on machine size, we performed additional simulations using $C$ and Fe in which the major and minor radius were varied in the following matrix:

$$
\begin{aligned}
& R=550,600,650 \mathrm{~cm} \\
& a=250,300,350 \mathrm{~cm} .
\end{aligned}
$$

To approximate the amount of power radiated as bremsstrahlung versus line radiation, a simple criterion was selected based on the location of the minimum in radiation power density. All power radiated from the region outside that point is called line radiation $\left(\mathrm{P}_{\mathrm{L}}\right)$ and all radiation from within that radius is assumed to be bremsstrahlung $\left(\mathrm{P}_{\mathrm{B}}\right)$. Thus, the dividing point belween the bremsstrahlung and line radiation regions is different for each impurity and depends upon the temperature and density profiles of the plasma, although it is usually at $r / a-0.85$.

One might expect that bremsstrahlung, emanating from the plasma core, would be volume-clependent and thus scale as $R^{*} a^{2}$, and that line radiation, coming mostly from the plasma edge, would depend on the amount of surface area available and hence be proportional to $R^{*} a$. Of course, this second approximation may not be good if the region of line radiation is fairly thick. But we can reasonably 
expect that $P_{T} \sim R^{*}{ }^{b}$, where $P_{T}=P_{L}+P_{B}$ and $1<b<2$. Empirically, we found the following scalings of radiated power with machine size:

Table 4. Scaling of radiated power with minor radius

\begin{tabular}{|c|c|c|c|c|c|}
\hline \multicolumn{3}{|c|}{ High Density } & \multicolumn{3}{|c|}{ Low Density } \\
\hline$\frac{\text { Impurity }}{\mathrm{C}}$ & $\frac{\text { Radiation }}{\mathrm{PL}_{\mathrm{L}}}$ & $\frac{\mathbf{b}}{1.08}$ & $\underset{c}{\text { Impurity }}$ & $\frac{\text { Radiation }}{\mathrm{P}_{\mathrm{L}}}$ & $\frac{\mathrm{b}}{1.08}$ \\
\hline & $\mathbf{P}_{\mathbf{B}}$ & 2.05 & & $\mathrm{P}_{\mathrm{B}}$ & 2.00 \\
\hline & $\mathbf{P}_{\mathrm{T}}$ & 1.62 & & $\mathbf{P}_{\mathbf{T}}$ & .59 \\
\hline $\mathrm{Fe}$ & $\mathbf{F}_{\mathbf{L}}$ & 2.14 & $\mathbf{F e}$ & $\mathbf{P}_{\mathbf{L}}$ & 1.81 \\
\hline & $\mathbf{P}_{\mathbf{B}}$ & 1.85 & & $\mathbf{P}_{\mathbf{B}}$ & 1.89 \\
\hline & $\mathbf{P}_{\mathbf{T}}$ & 2.02 & & $\mathbf{F}_{\mathbf{T}}$ & 1.85 \\
\hline
\end{tabular}

In gentral, medium-Z impurities like Fe have radiation power levels which are volume-dependent $\left(\mathrm{P}_{\mathrm{T}} \sim \mathrm{R}^{*} \mathrm{a}^{2}\right)$. The line radiation reglon for $\mathrm{C}$ is confined more closely to the wall, giving $\mathrm{P}_{\mathrm{T}}$ a weaker dependence on the minor radius. The high density case has a plasma volume which is roughly 1.5 times that of the low density case, but it yields radiated power levels which are about four times higher for $C$ and eight times higher for Fe (see Figs. $3 \mathrm{a}$ and $3 \mathrm{~b}$ ). This indicates that the density and temperature profiles - as well as transport rates - are more important than machine size in the comparison of impurity radiation from the two ITER configurations. Figure 5 shows the dependence of (total radiated power/major radius) versus minor radius for carbon in both the high density and low density ITER scenarios. Results from CIT simulations, to be described later, are also shown for comparison.

Figures $6 \mathrm{a}$ and $6 \mathrm{~b}$ show the power radiated at each radius (dotted lines) and the integrated power from $r=0$ outward (solid lines) of $\mathrm{He}, \mathrm{C}, \mathrm{D}, \mathrm{Fe}$ and $\mathrm{W}$, for both density cases, diffusivity $D=0.3 \mathrm{~m}^{2} / \mathrm{s}$, and zero convective velocity. The radiation 
from the central region $(\tau-0)$ is nearly all bremsstrahlung, with the exception of that from $W$ in the high density case. Radiation from the edge is essentially line radiation. Elements with few electrons, e.g., helium, radiate little from the edge. From this type of data we can extract the amount of power radiated from various regions. There are three regions for which we have performed caiculations: the plasma core defined by $\mathrm{r} / \mathrm{a}<0.3$, the edge region $(0.9<\mathrm{r} / \mathrm{a}<1.0)$, and the scrape-off layer (SOL), i.e., $r / a>1$. In Fig. 7 are plotted, for $D(r)=$ constant, the fractlons of power radiated by each impurity from $r / a>0.9$, the edge and SOL reglons. (These fractions differ little from the $D(r)$ monotonically increasing case.) For the ITER mix of impurities and a weak inward convection, the radiated power from the edge is $-50 \%$ of the total radiated power.

Figures $8 a$ and $8 b$ show the effect of pinch velocity on edge and core radiation for $D=0.3 \mathrm{~m}^{2} / \mathrm{s}$. Edge radiation decreases and core radiation rises with stronger impurity pinch velocities. Fe radiation decreased as a result of convection, producing only $60-75 \%$ of the power at $C_{\mathrm{Vr}}=10$ that it had without a convective velocity. It is significant to note that the desired edge radiation of $C$ and $F e$ falls below $25 \%$ of the total power when $C_{v r}$ is $\sim 2$ or greater.

Figure 9 shows the radiation from the scrape off region, again for $D=0.3 \mathrm{~m}^{2} / \mathrm{s}$ and no inward convection. In these MIST code simulations, the fraction of impurity radiation from the SOL is seen to be only a few percent of the total radiated power. However, this model ignores the complexities of 2-d flows in the scrape-off and divertor regions and is likely to be an underestimate. For example, intense impurity recycling and broader electron temperature profiles could increase carbon radiation dramatically, as predicted recently. 11 In addition, the choice of plasma 
edge temperature can have a dramatic effect on the amount of power radiated fiom the SOL. To illustrate this, simulations with $C$ and Fe were made in which the temperature at the separatrix was varied in the range $20-300 \mathrm{eV}$, but both the sharp temperature falloff in the SOL and the slower rise towards the core were maintained (see Table 1). The graphs in Fig. 10a show that carbon radiation is much stronger with an edge temperature below $50 \mathrm{eV}$, increasing by about $50 \%$ above its level at $T_{e}(a)=200 \mathrm{eV}$. Edge radiation increases at lower temperatures because inflowing impurities can exist in rather low charge states, which are favorable for line radiation. Since this radiation will cool the plasma, this could lead (in a study with time-dependent temperature profiles and the associated time-dependent impurity generation processes) to either a periodic variation or sieady-state behavior of impurity generation, impurity radiation, plasma edge cooling, and enhanced edge radiation, depending on the feudback processes. Note in Fig. $10 \mathrm{~b}$ that the total Fe radiation increases $<25 \%$ when the edge temperature is lowered to $50 \mathrm{eV}$. This smaller effect is due to the broader region from which Fe radiates. The drop in Fe radiation at the lowest electron temperature studied is due to the combined effects of the sharper electron temperature profile and the radiation rate as a function of temperature. 21

Using the 1988 impurity concentrations specified for ITER, the radiation from the impurities has been calculated. Figures $11 \mathrm{a}$ and $11 \mathrm{~b}$ show histograms of the radiation from each element for two values of $D$. Additionally, a bar has been put in for $W$ to show what a 0.1 increase in $Z_{\text {eff }}$ from $W$ would contribute. In the ITER plasma, Fe would create roughly half the impurity ridiation and $C$ would contribute about one-fourth. Figure 11c shows the predicted total radiation of each imipurity in 
ITER using the $1989 Z_{\text {eff }}$ specification. Again, a trace amount of $W, \Delta Z_{\text {eff }}=0.1$, is included for comparison.

Figure 12a shows, for the 1988 fixed impurity concentrations specified for ITER, the expected total radiated power for the range of diffusivities considered. Low density discharges radiate $30-130 \mathrm{MW}$, depending on the values of transport coefficients. This radiation, by itself, is inadequate, especially considering that low density discharges are likely to use more extensive amounts of auxiliary power to accomplish their goal of steady-state operation. Perhaps recycling, synchrotron sadiation, or the addition of small amounts of high- $Z$ materials would improve this situation sufficiently. Figure $12 \mathrm{a}$ also shows that high density discharges radiate >200 MW, far more than necessary or desirable. The controlled reduction of impurities in this case is seen to be required. Figure $12 \mathrm{~b}$ shows the effects of the 1989 $Z_{\text {eff }}$ specification. The reduction in radiated power at high density is beneficial, while the increase at low density is insufficient to reduce the divertor heat load. 


\section{$3.2 \mathrm{CIT}$}

Using the parameters in Table 2, a study of impurity radiation from CIT was made. With diffusivities in the range $0.1-1.0 \mathrm{~m}^{2} / \mathrm{s}$ (see Fig. 13), impurities in CIT would radiate about $20-30 \mathrm{MW}$. This is to be compared with the $100 \mathrm{MW}$ of alpha heating power which is expected from the ignited plasma. 20 Figures 14,15 and 16 show that the impurity radiation of CIT, which is produced solely by carbon, acts qualitatively like that of ITER. Edge radiation is enhanced by nigher values of $D$ and by lower edge temperatures. A higher central temperature slightly increases the fraction of core radiation. For the standard values $D=0.3 \mathrm{~m}^{2} / \mathrm{s}, T_{\mathrm{e}}(\mathrm{a})=100 \mathrm{eV}$ and $T_{e}(0)=20 \mathrm{keV}$, edge radiation represents between $30 \%$ and $40 \%$ of the total power.

H-mode discharges, with broader density profiles and cooler edge regions than pellet-fueled discharges, would bensfit more from higher radiated power levels and a larger fraction of the radiation originating from $r / a>0.9$, especially if there were no inward convection.

In Fig. 5, the minor radius scaling for CIT impurity radiation is compared with that found for ITER. Two CIT cases are shown, one for H-mode at the standard density, $\left\langle n_{e}\right\rangle=5.25 \times 10^{14} \mathrm{~cm}^{-3}$, and the other for H-mode operation at a lower density, $\left\langle\pi_{e}\right\rangle=1.4 \times 10^{14} \mathrm{~cm}^{-3}$. Both use the same transport coefficients, $D=0.3 \mathrm{~m}^{2} / \mathrm{s}$ and $C_{\mathrm{vr}}=0.1 \mathrm{~m} / \mathrm{s}$. With the same $<n_{\mathrm{e}}>$ as ITER, CIT radiates less power because the region of $\operatorname{low}$ temperature is more narrow and because a weaker influx is required to maintain the same concentration of $C$. Both are due to the smaller minor radius of CIT. Thus, the scaling laws decribed in Table 4 are only valid locally, near a $-3 \mathrm{~m}$. 


\section{Discussion}

These calculations have corroborated the importance of impurity radiation on the operation of reactor-like tokamaks. "Clean" tokamaks, with $\mathrm{Z}_{\text {eff }}<2$, may be able to operate in a borderline region, where the impurity-radiated power level is large enough to reduce power Joads on divertors and limiters and small enough to avoid disruptions or quench of ignition.

The accuracy of these predictions depends upon the accuracy of the atomic physics inputs. Experimental data, though limited, do give confidence that the accuracy of the atomic physics data is better than a factor of 2. However, this is insufficient to assess the full impact of impurity content on fusion reactors and reactor prototypes. Also important to the accuracy of the radiated power calculations are the exact temperature and density profiles in the edge plasma. These, in conjunction with the transport rates, determine the radiated power, particularly in the edge region. Hence, a full self-consistent treatment of the SOL, edge region and plasma core is necessary.

\section{Acknowledgments}

This work supported by U.S. Department of Energy Contract No. DE-AC02-76CHO3073, the National Science Foundation Graduate Fellowship and the John and Fannie Hertz Foundation. 


\section{References}

[1] R. G. Mills, ed., Princeton Plasma Physics Laboratory Report No. MATT-105C, or Y. Shimomura, Nucl. Fusion 17, 626, (1977).

[2] K. Tomabechi, Plasma Phys. Controlled Nuclear Fusion Research 1988 (Proc.

12-th Conference, Nice, 1989) Vol. 3, IAEA-CN-50/F-I-4, 215.

[3] M. Petravic, et al., Phys. Rev. Lett. 48, 326, (1982).

[4] M. Harrison and E. S. Hotston, INTOR Phase IIA., IAEA 1987.

[5] S. A. Conten, et al,, (to appear in J. Nuc. Mater.) ana K. Werley, S. A. Cohen, and B. Braams, ITER-IL-Ph-13-9-U-I (1989).

[6] J. Brooks, j. Nucl. Mater. 170, 164 (1990).

[7] R. Hulse, Nucl. Technol./Fusion 3, 259, (1983).

[8] Y. Shimomura, Plasma Phys. Controlled Nuclear Fusion Research 1988 (Proc. 12-th Conference, Nice, 1989) Vol. 3, IAEA-CN-50/F-II-4, 273.

[9] M. H. Redi and S. A. Cohen, Princeton Plasma Physics Laboratory Report No. PPPL-2641.

[10] D. E. Post, Plasma Phys. Controlled Nuclear Fusion Research 1988 (Proc. 12-th Conference, Nice, 1989) Vol. 3, IAEA-CN-50/F-II-1, 233.

[11] A. Abramov, Yu. Igitkhanov, and V. Pistunovitch, ITER-IL-Ph-13-9-S-12, (1989).

[12] P. H. Rebut and B. G. Green, Plasma Phys. Controlled Nuclear Fusion Research (Proc. 6-th Conference, Berchtesgaden, 1976) Vol. 2, IAEA, Vienna (1977) 3.

[13] K. Borrass, NET Report, EUR-FU/80/89-95.

[14] D. E. T. F. Ashby and M. H. Hughes, Nucl. Fusion 21, 911, (1981).

[15] K. L. Bell, et al., J. Phys. Chem. Ref. Data 12, 891, (1983).

[16] J. E. Rice, E. S. Marmar, E. Källne, and J. Källne, Phys. Rev. A 35, 3033, (1987).

[17] K. Ida, R. J. Fonck, S. Sesnic, R. A. Hulse, and B. LeBlanc, Phys. Rev. Lett. 58, 116, (1987).

[18] S. P. Hirshmann, Phys. Fluids 19, 155, (1976). 
[19] P. Tiger, et al., Princeton Plasma Physics Laboratory Applied Physics Division Report No. 23.

[20] ]. A. Schmidt, Princeton Plasma Physics Laboratory Controlled Document No. AE-891018-PPL-01, Revision 0.

[21] D. E. Post, et al., At. Data Nucl. Data Tables 20, 397, (1977).

[22] D. P. Stotler and G. Bateman, Fusion Technol. 15, 12, (1989). 


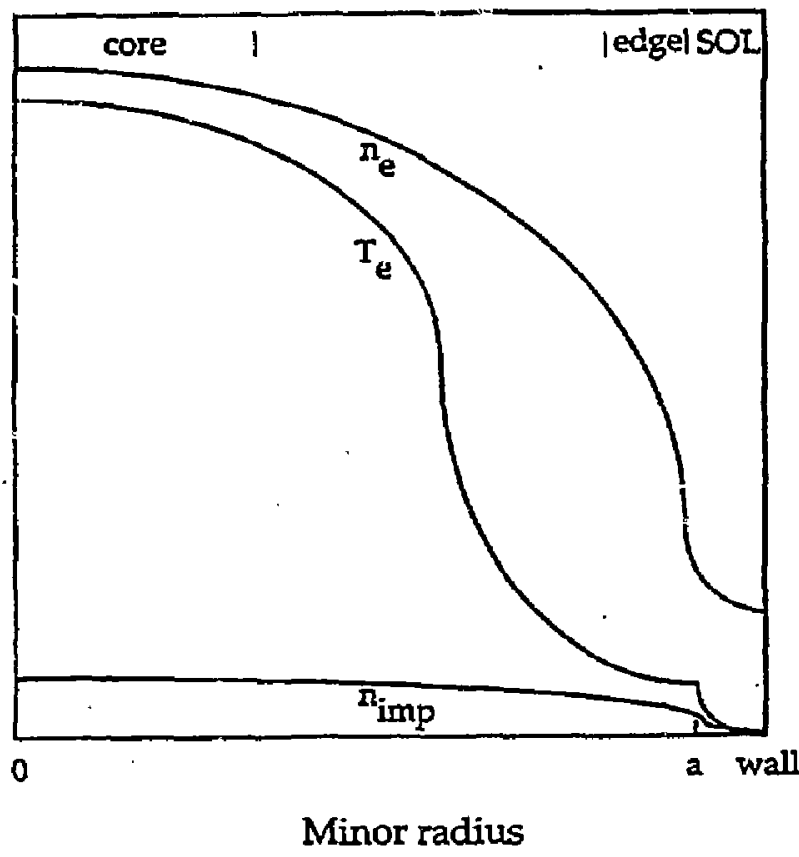

Fig. 1. Schematic of the density and temperature profiles in ITER and CIT. Also shown are the regions defined by the terms core, edge and scrape-off layer (SOL). 


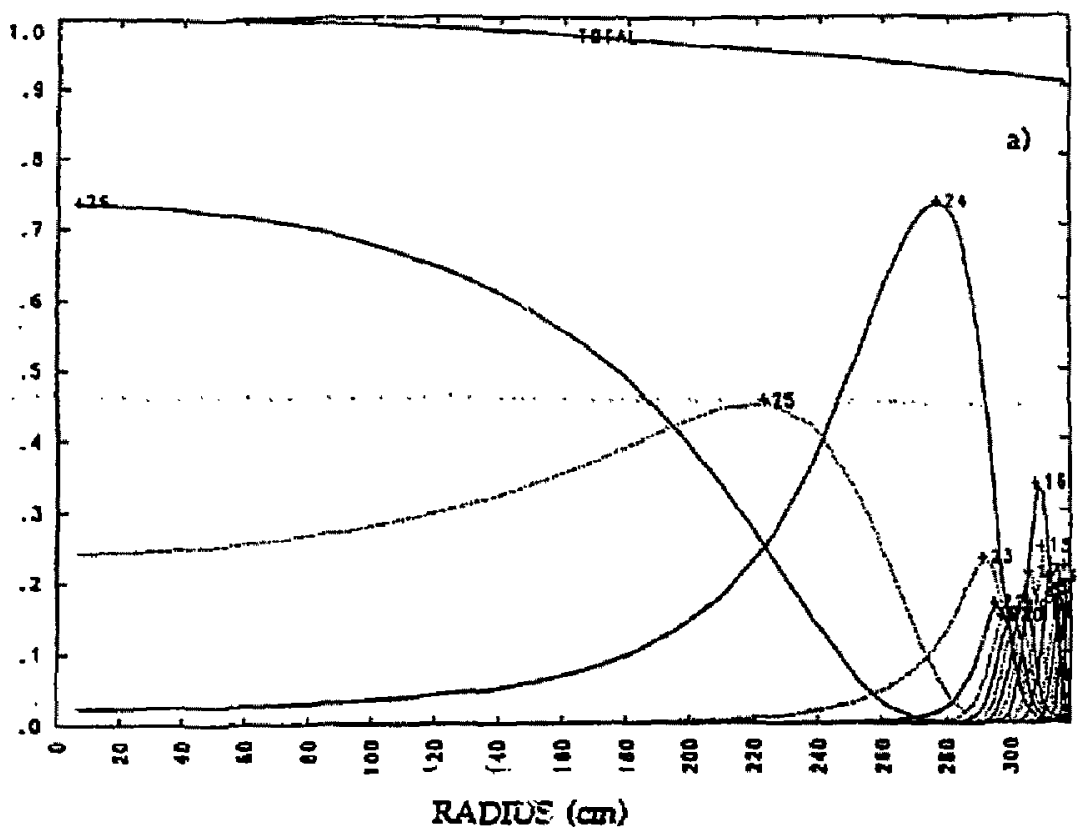

Fig. 2a. Calculated density profiles for Fe ions in ITER, for a particular set of transport and plasma parameters.

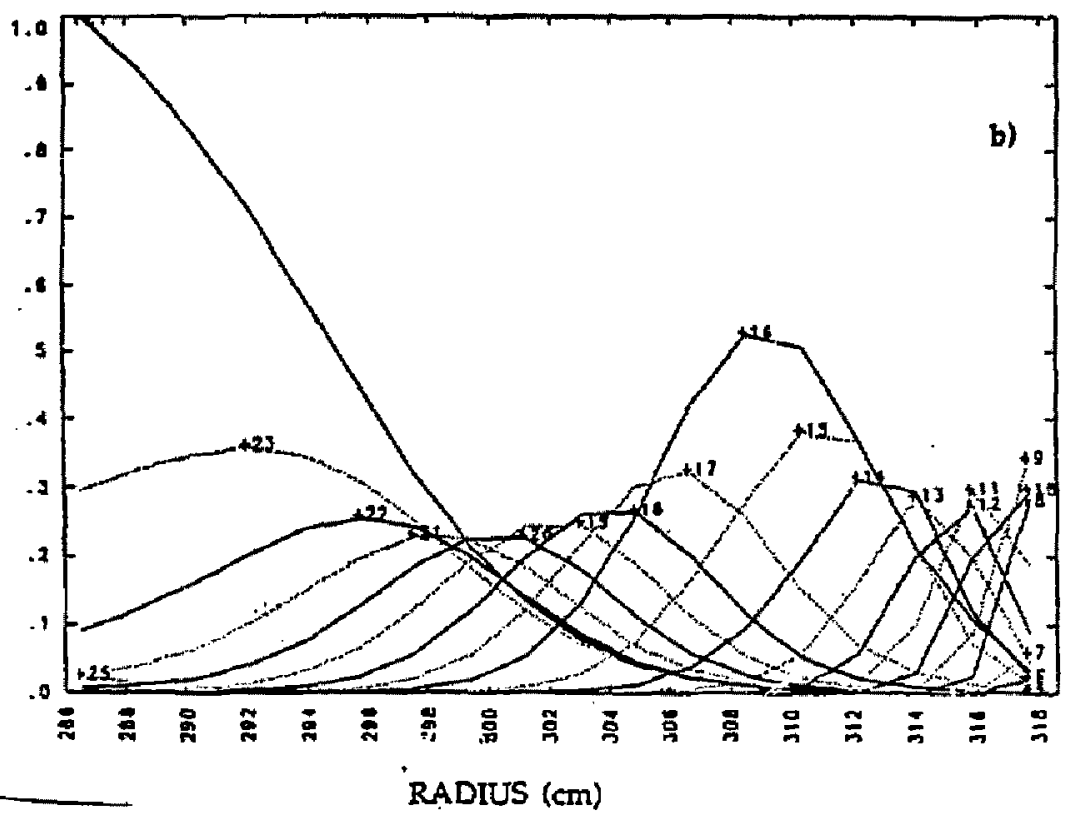

Fig. $2 b$. High resolution display of the Fe ion densities in the edge region for the
same parameters as in Fig. $2 \mathrm{a}$. 
Effect of High-Reșolution Mesh Size on

Fe Radiation; $D=3.0 \mathrm{e} 4 \mathrm{~cm}^{\wedge} 2 / \mathrm{s}, V=0 \mathrm{~cm} / \mathrm{s}$

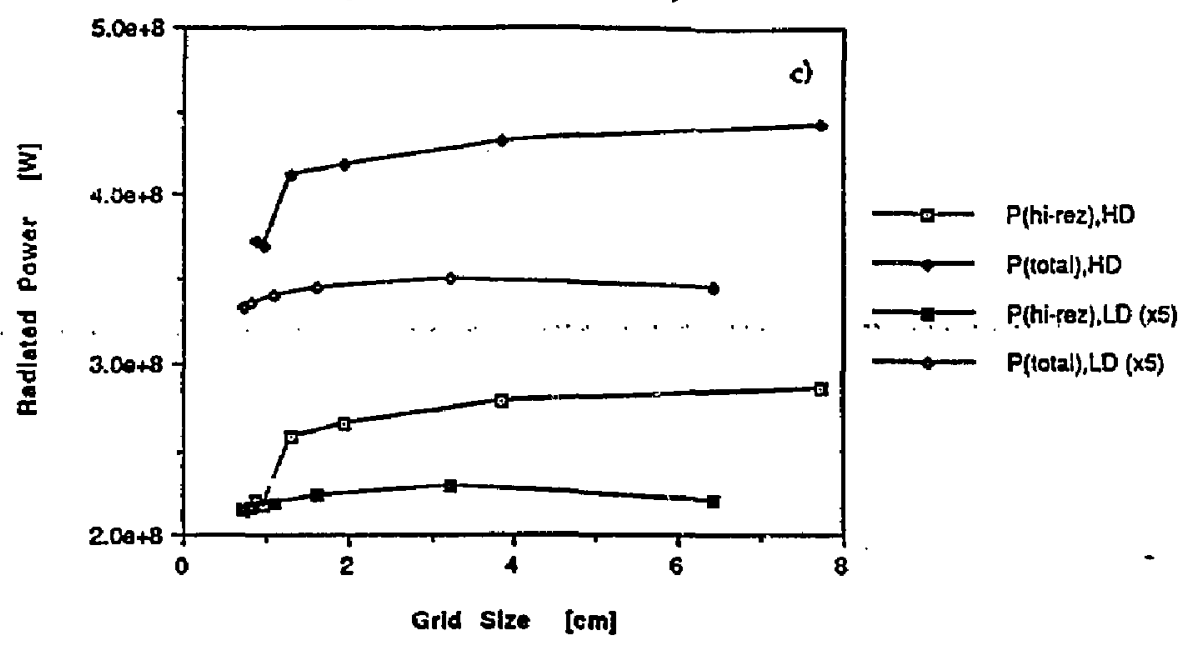

Effect of High-Resolution Mesh Size on

C Radiation; $D=3.0 e 4 \mathrm{~cm}^{\wedge} 2 / \mathrm{s}, V=0 \mathrm{~cm} / \mathrm{s}$

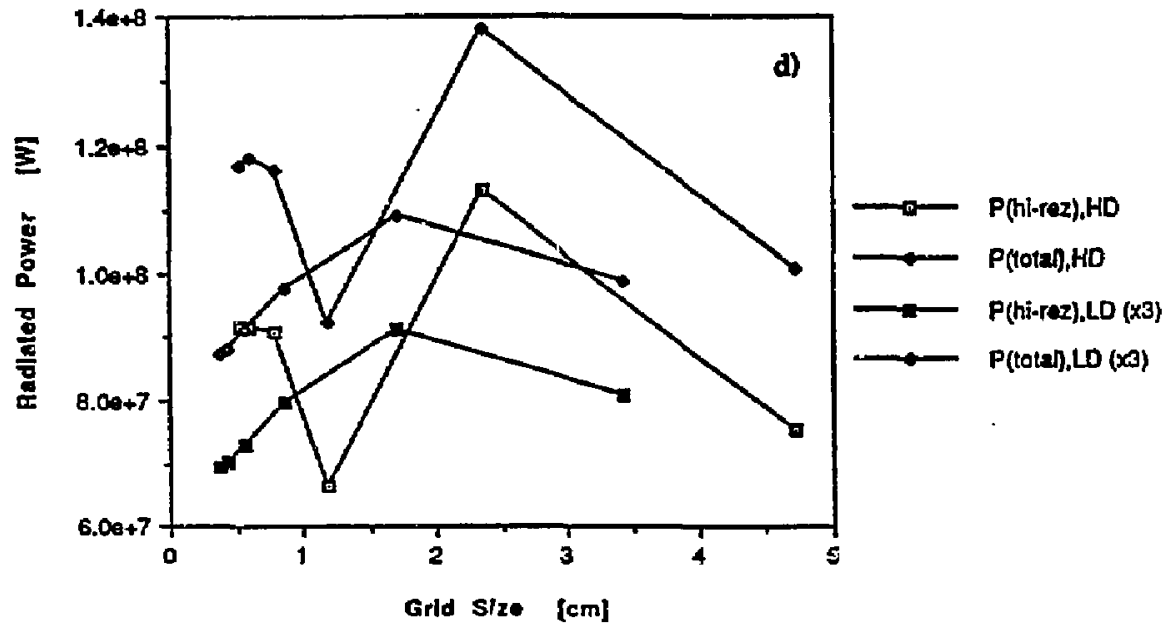

Fig. 2c. Effect of mesh size on radiated power for Fe in both high (H) and low (L) density discharges. Both total radiated power and that from just the high resolution region are shown.

Fig. 2d. Effect of mesh size on radiated power for $C$ in both high (H) and low (L) density discharges. Both total radiated power and that from just the high resolution segion are shown. 


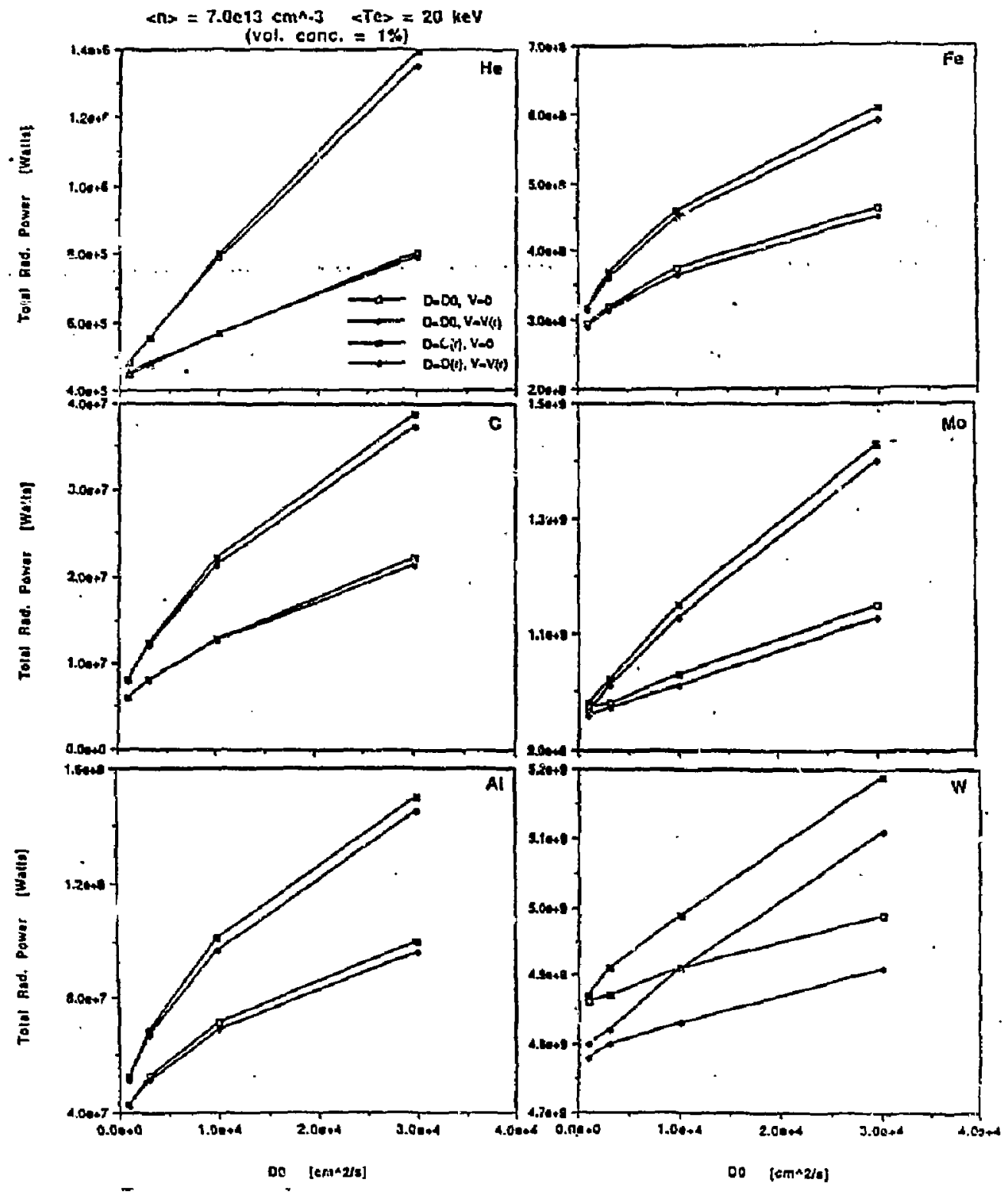

Fig. 3a. Calculated radiated power from low density ITER plasmas as functions ot transport parauneters and element. The volus;e-averaged plasma parameters are $\left\langle\mathrm{n}_{\mathrm{e}}\right\rangle=7.0 \mathrm{e} 13 \mathrm{~cm}^{-3}$ and $\left\langle\mathrm{T}_{\mathrm{e}}\right\rangle=20 \mathrm{keV}$. The volume-averaged impurity content is fixed at $1 \%$ of the electron density. 

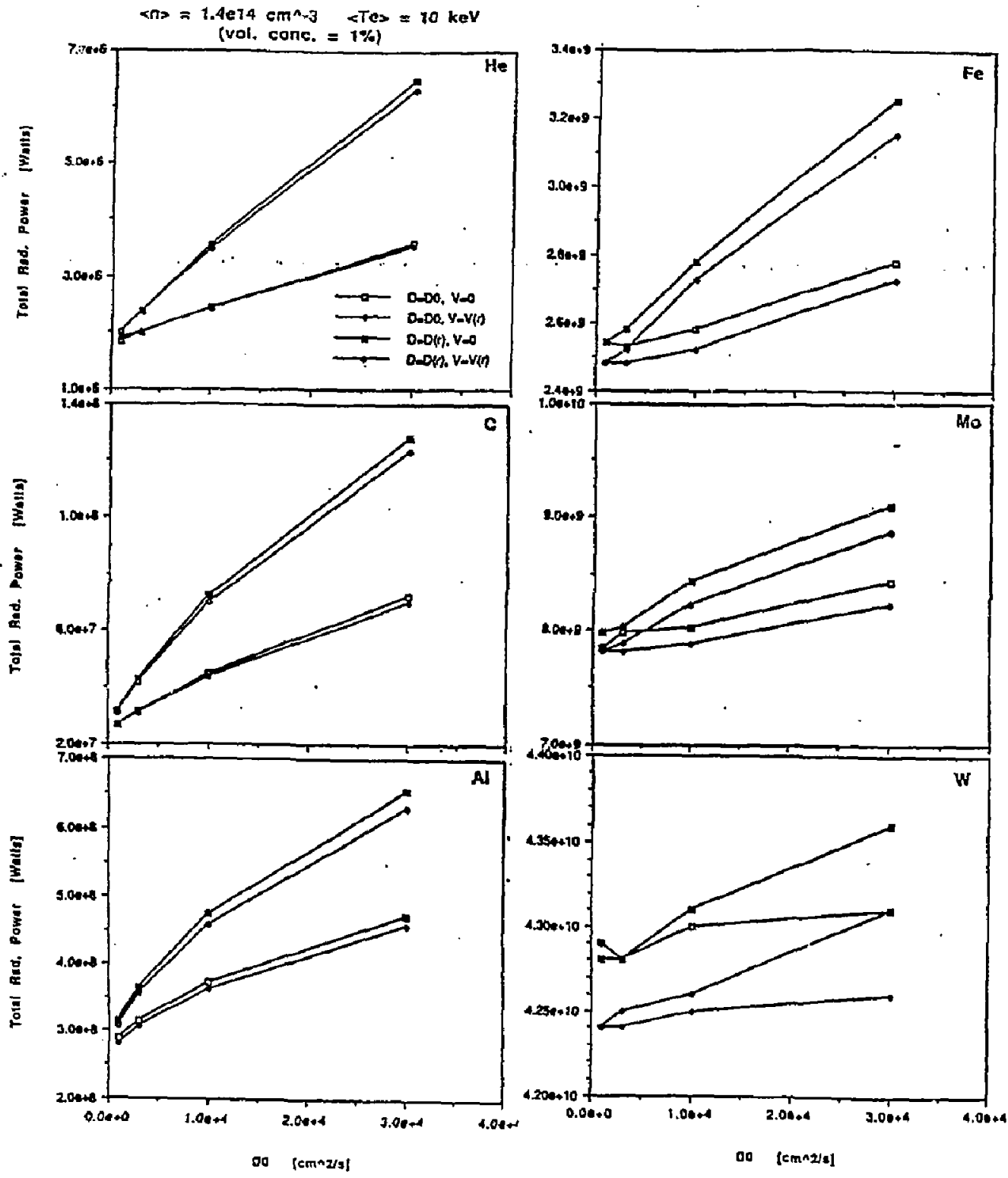

Fig. 3b. Calculated radiated power from high density ITER plasmas as functions of transport parameters and element. The volume-averaged plasma parameters are $\left\langle n_{\mathrm{e}}\right\rangle=1.4 \mathrm{e} 14 \mathrm{~cm}^{-3}$ and $\left\langle\mathrm{T}_{\mathrm{e}}\right\rangle=20 \mathrm{keV}$. The volume-averaged impurity content is fixed at $1 \%$ of the electron density. 


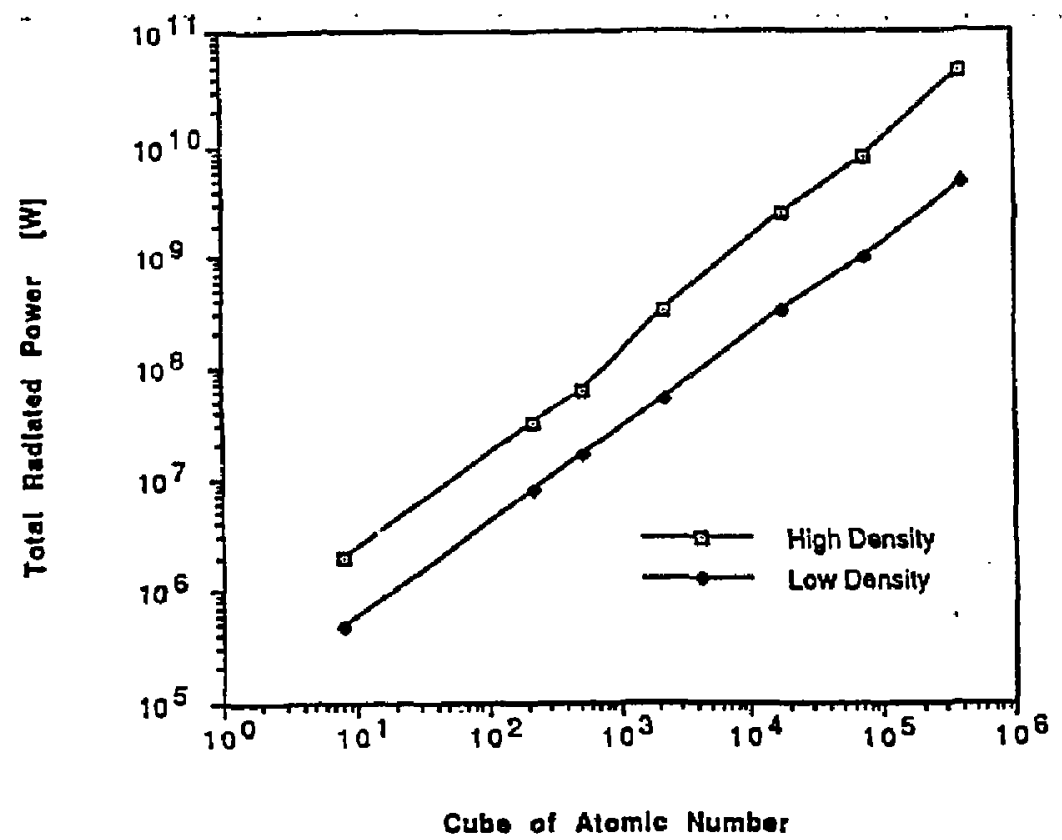

Fig. 4. Radiated power yersus $Z^{3}$ for various elements at $1 \%$ concentrations in low and high density ITER plasmas. The diffusion and convection coefficients employed were $D=0.3 \mathrm{~m}^{2} / \mathrm{s}$ and $\mathrm{v}=0 \mathrm{~m} / \mathrm{s}$. 


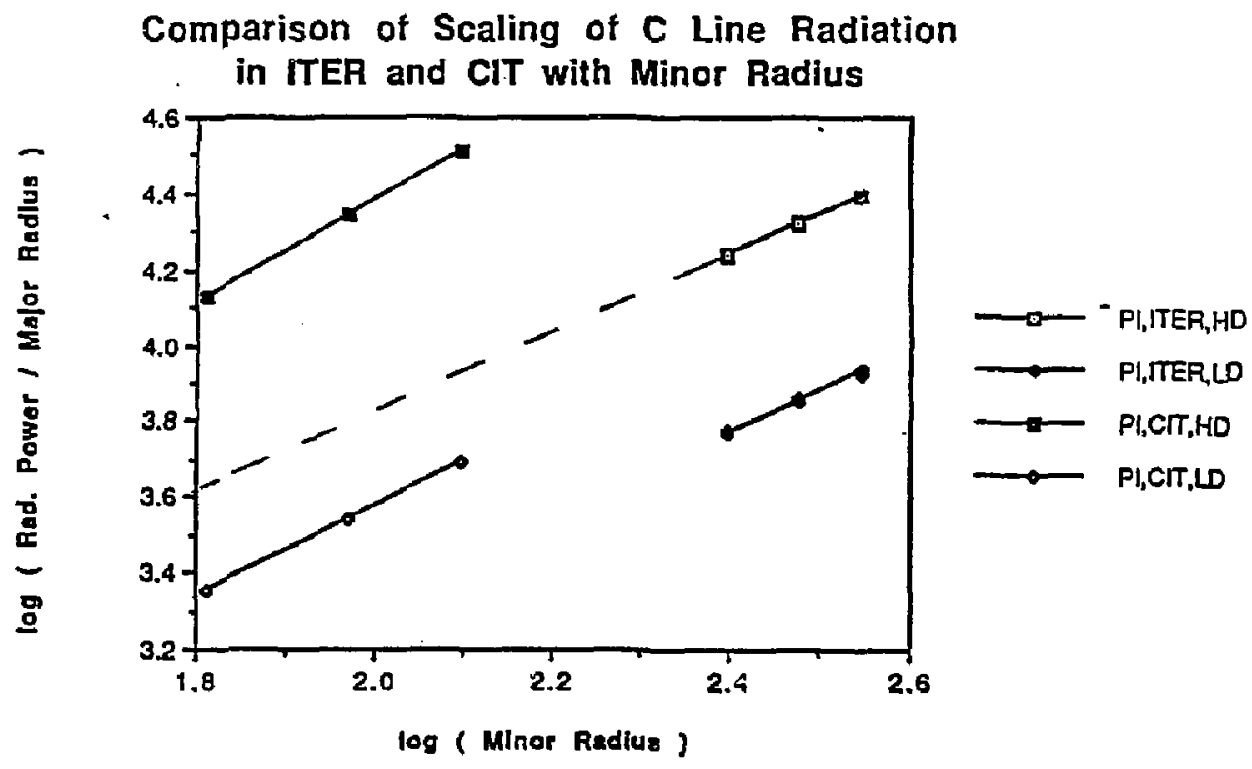

Fig. 5. Scaling of impurity radiation with minor radius for high and low density (HD, LD) ITER plasmas and for CIT plasmas, also of two different densities. The CIT simulations with the higher radiation have parameters described in the text ( $H$-mode confinement, Table 2). The CIT simulations resulting in lower radiated power have a lower density: $\left\langle n_{e}\right\rangle=1.4 e 14 \mathrm{~cm}^{-3}$, as in the HD ITER runs. 

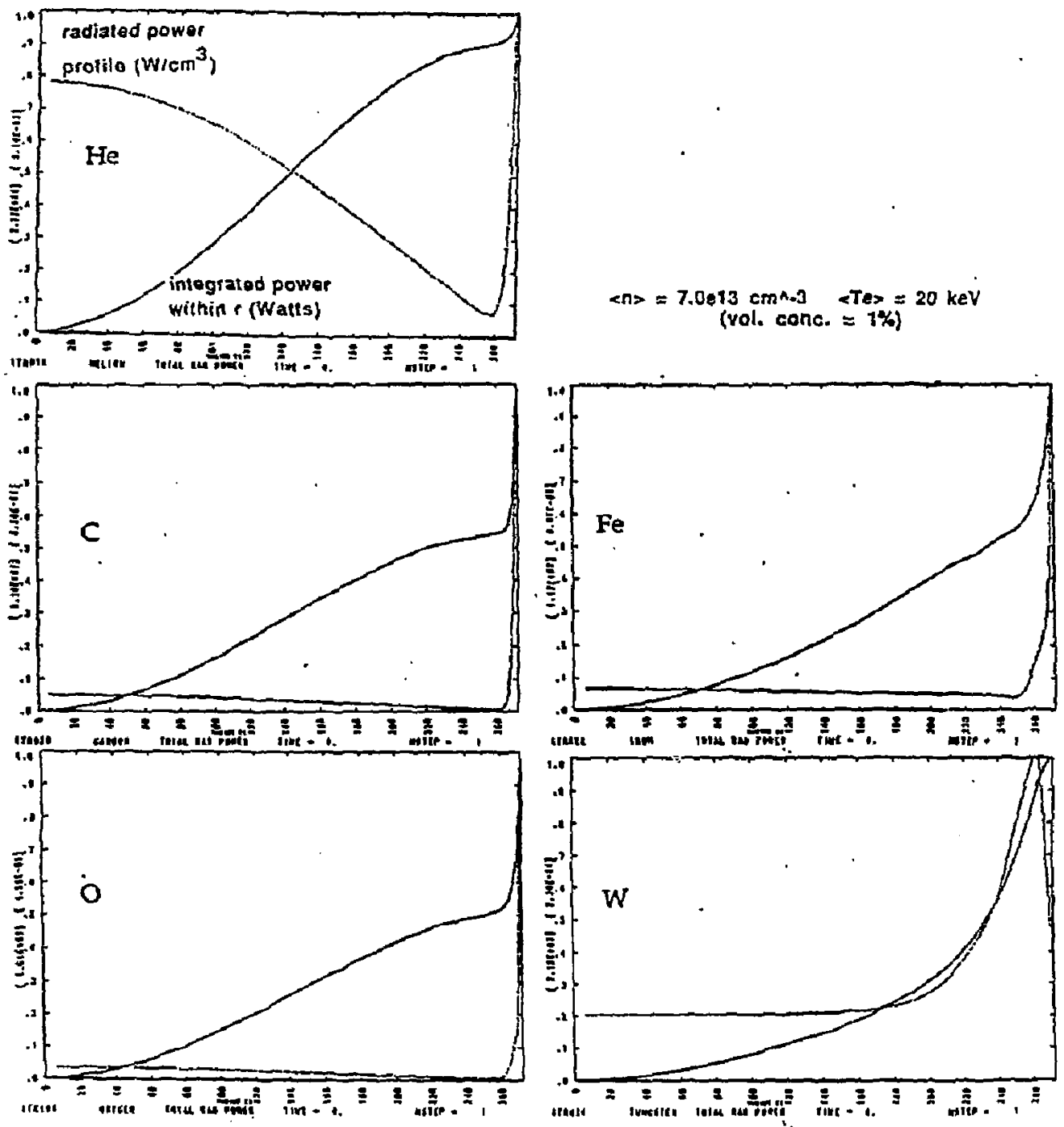

Fig. 6a. Radiated power (.......) and volume-integrated power out to $\mathrm{r}(\ldots$, both as sunctions of $\mathrm{I}$ for $\mathrm{He}, \mathrm{C}, \mathrm{O}, \mathrm{Fe}$ and $\mathrm{W}$ in low density ITER plasmas. 


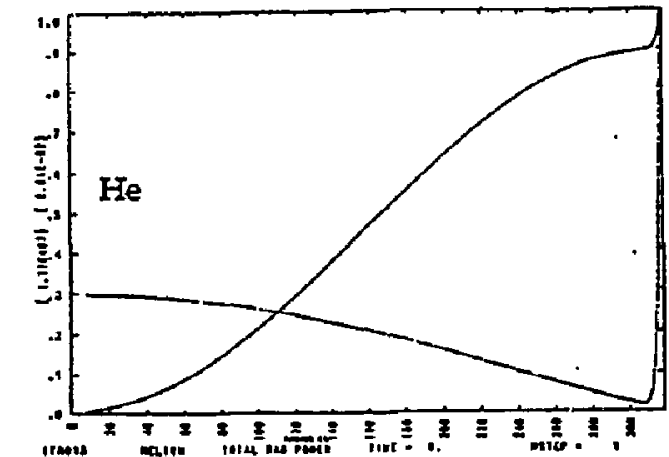

$<n>=1.4614 \mathrm{~cm}^{n-3} \quad<T e x=10 \mathrm{keV}$

(vol. conc. $=1 \%$ )
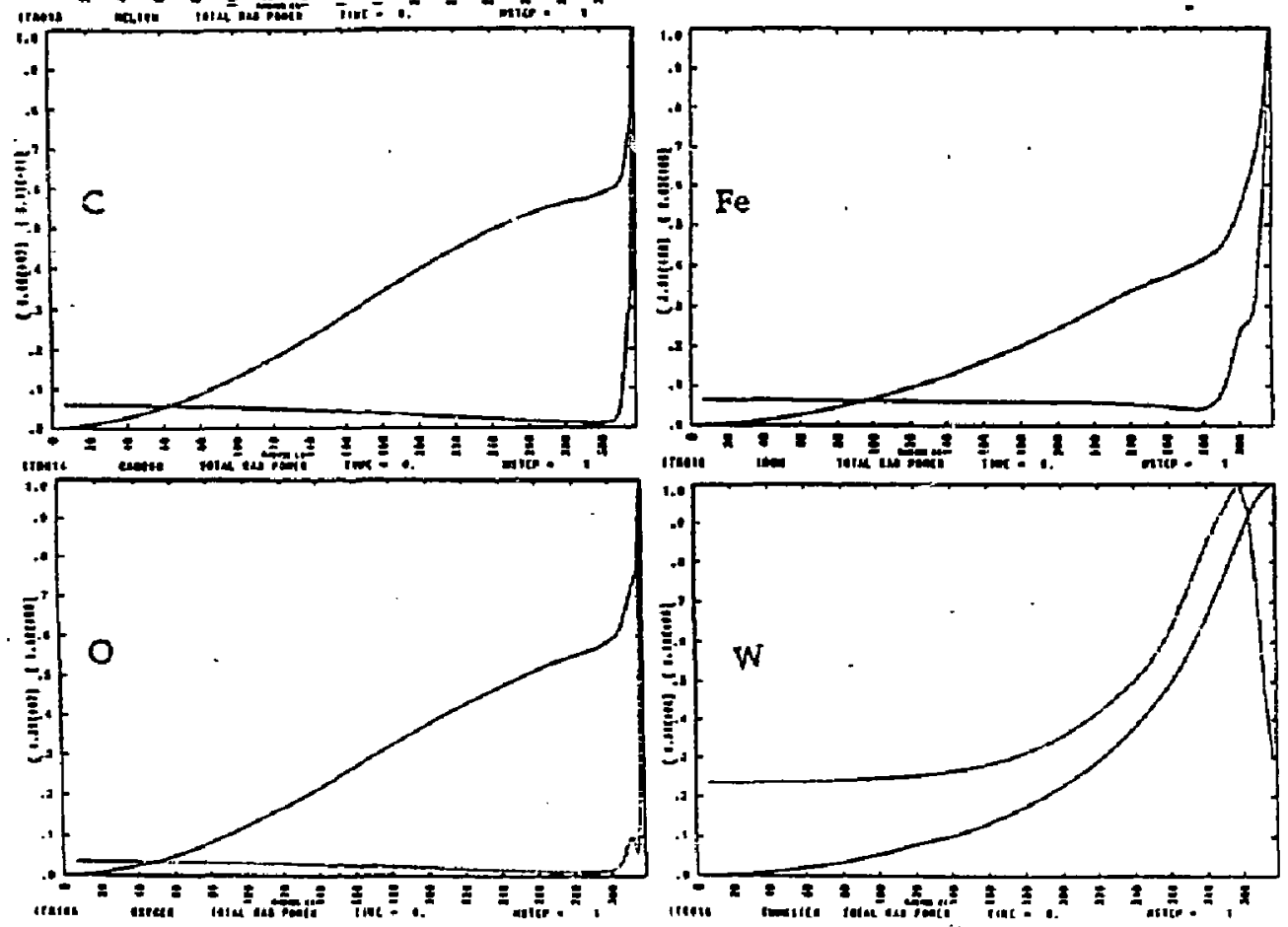

Fig. 6b. Radiated power (......) and volume-integrated power out to $\mathrm{r}($, both as functions of $r$ for $\mathrm{He}, \mathrm{C}, \mathrm{O}, \mathrm{Fe}$ and $\mathrm{W}$ in high density ITER plasrnas. 


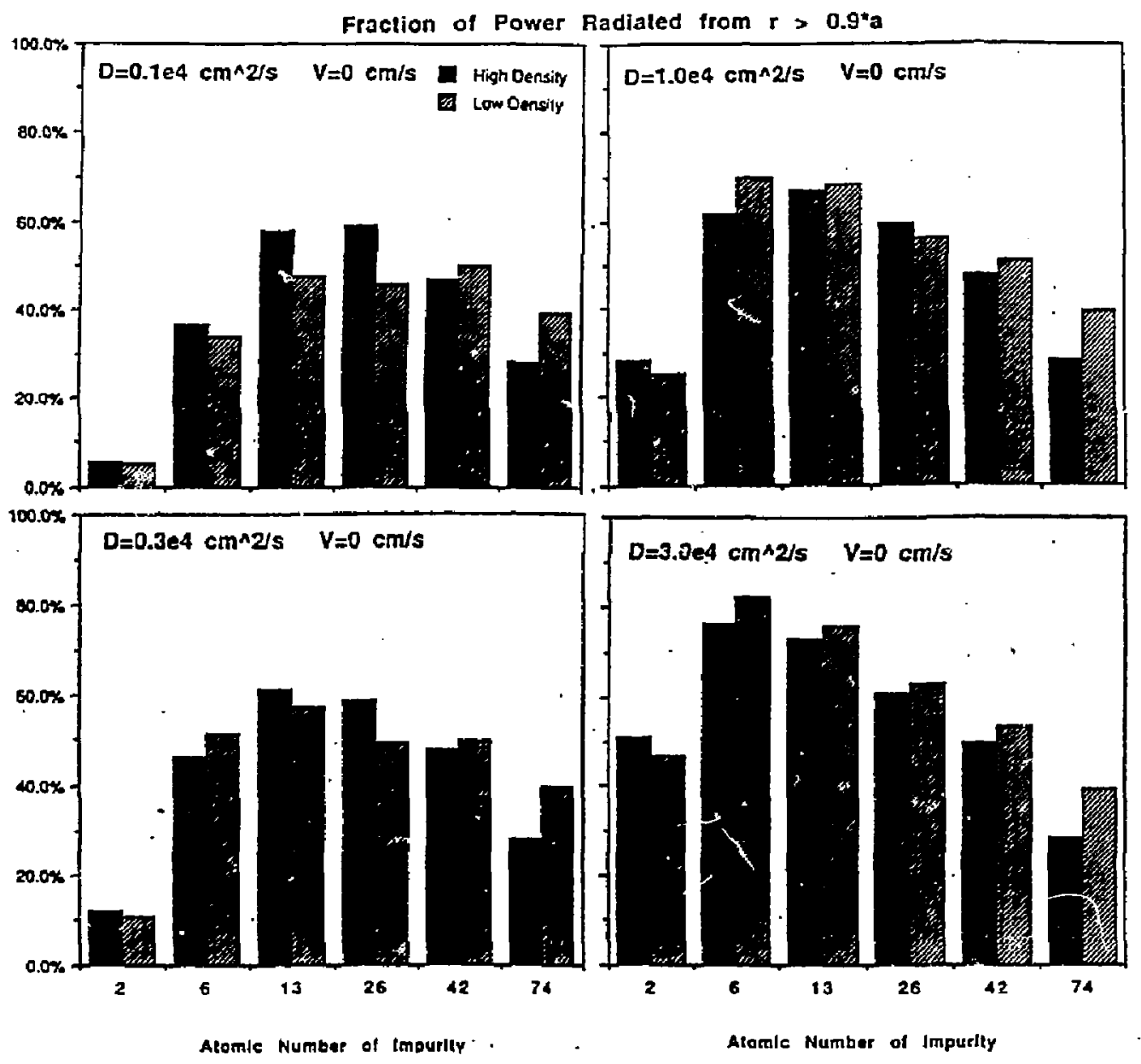

Fig. 7. Fraction of $\Gamma$ ower radiated from the edge and SOL regions of ITER for both high and low density cases, for 4 diffusivitiss. 

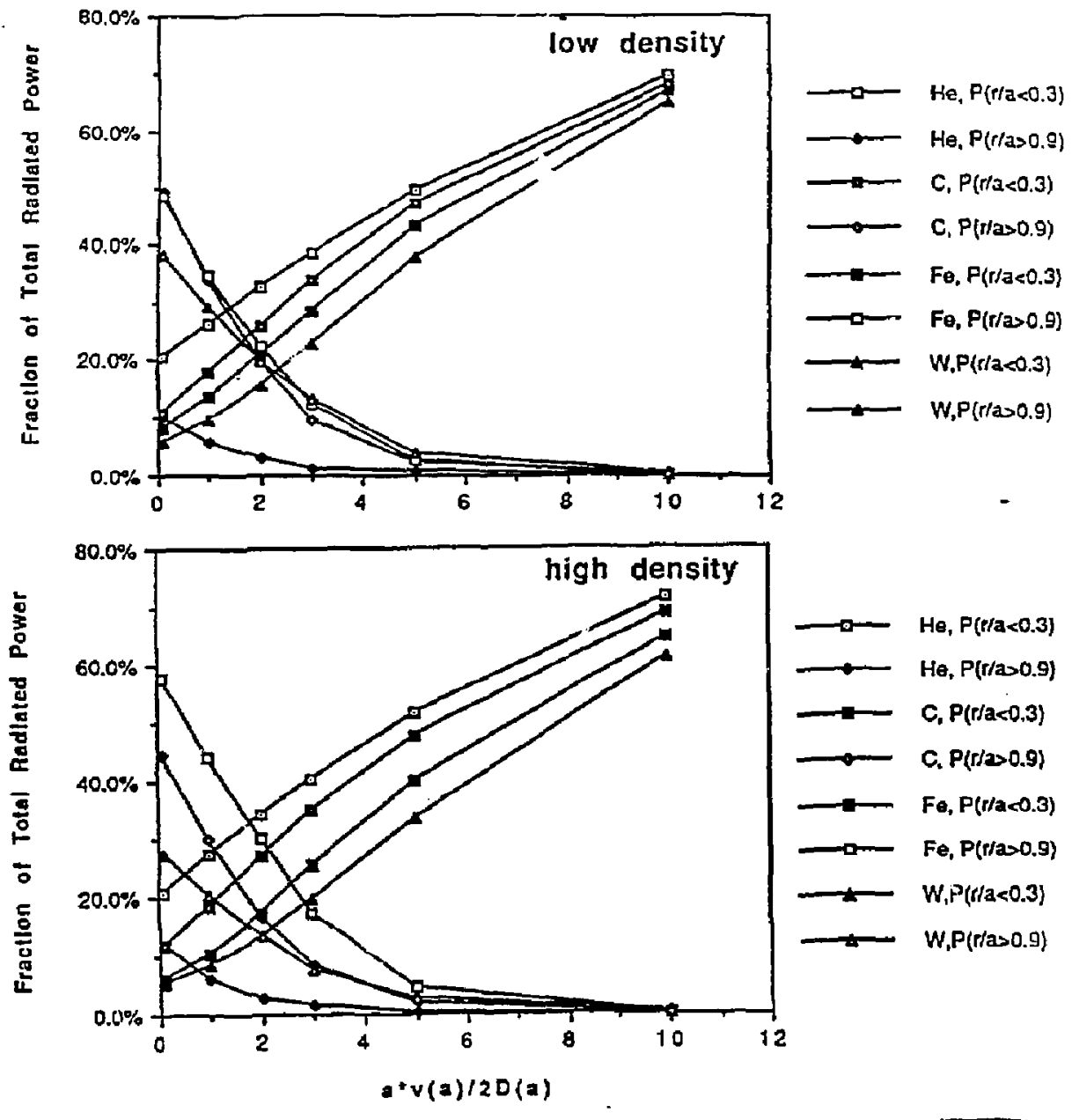

Figs. $8 \mathrm{a}$ and 8 b. Power radiated by impurities from different regions of low (a) and high (b) density ITER discharges, as functions of impurity inward convection velocity. 
Scrape-Off-Layer Impurity Radiation $D=0.3 e 4 \mathrm{~cm}^{\wedge} 2 / \mathrm{s} \quad V=0 \mathrm{~cm} / \mathrm{s}$

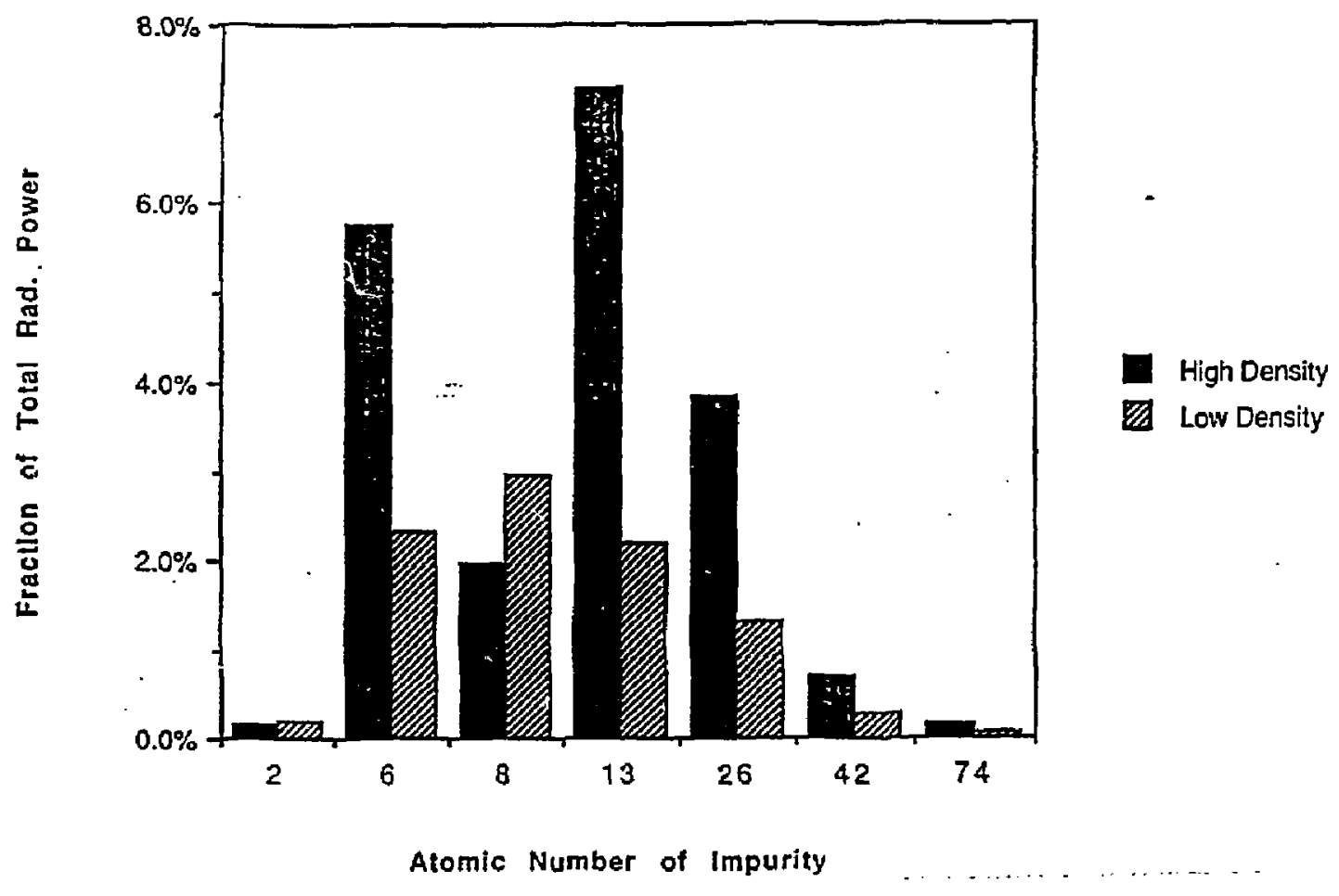

Fig. 9. Fraction of power radiated by inpurities in the ITER SOL. This fraction is expected to be a lower limit because MIST code simulations do not include 2-d effects known to increase impurity radiation. 


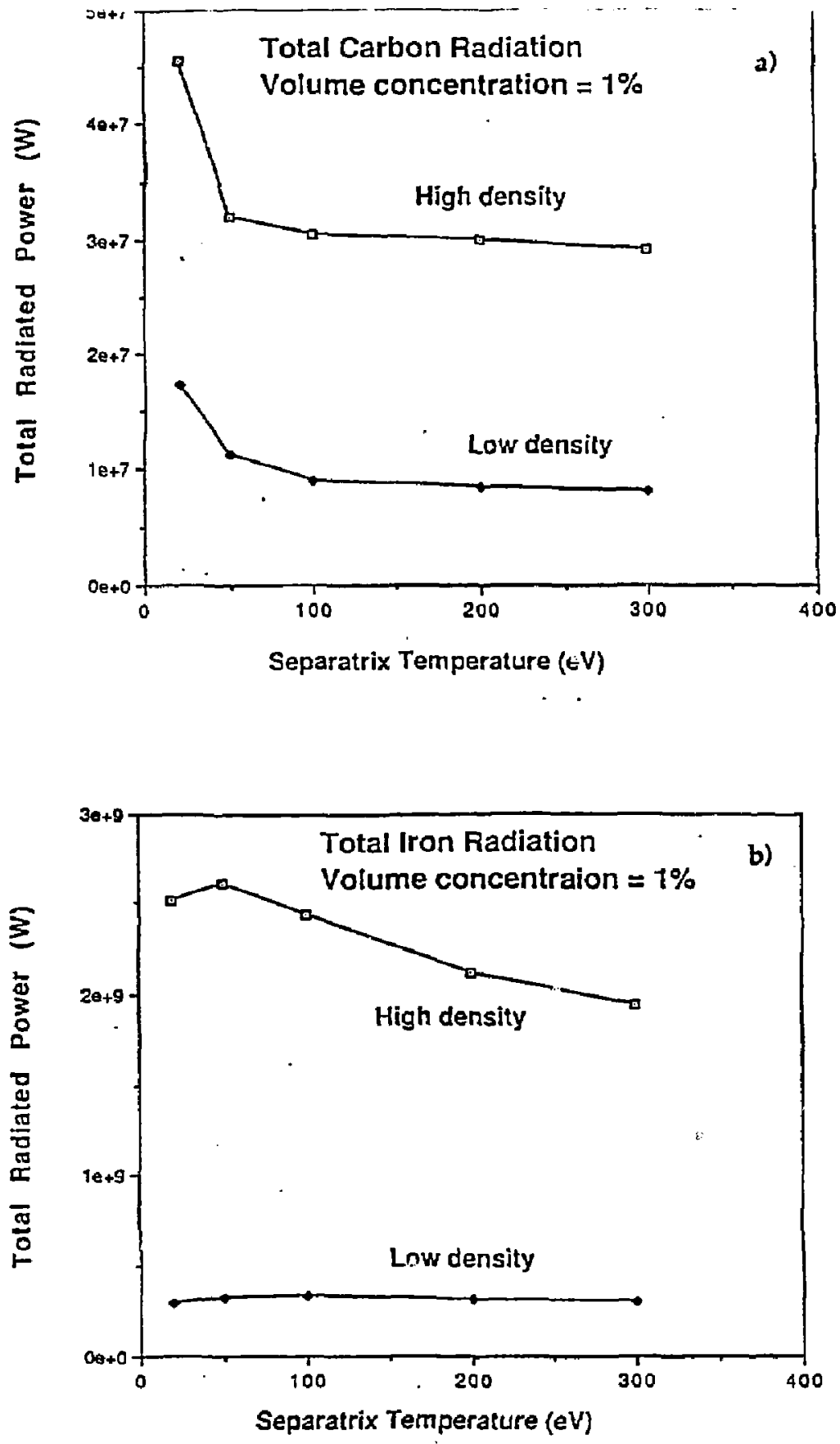

Fig. 10. Total radiation from $C(a)$ and $F e(b)$ as a function of separatrix temperature for the two ITER cases studied. In both, the radiation is normalized to a $1 \%$ volume concentration, which is greater than the expected concentrations. 

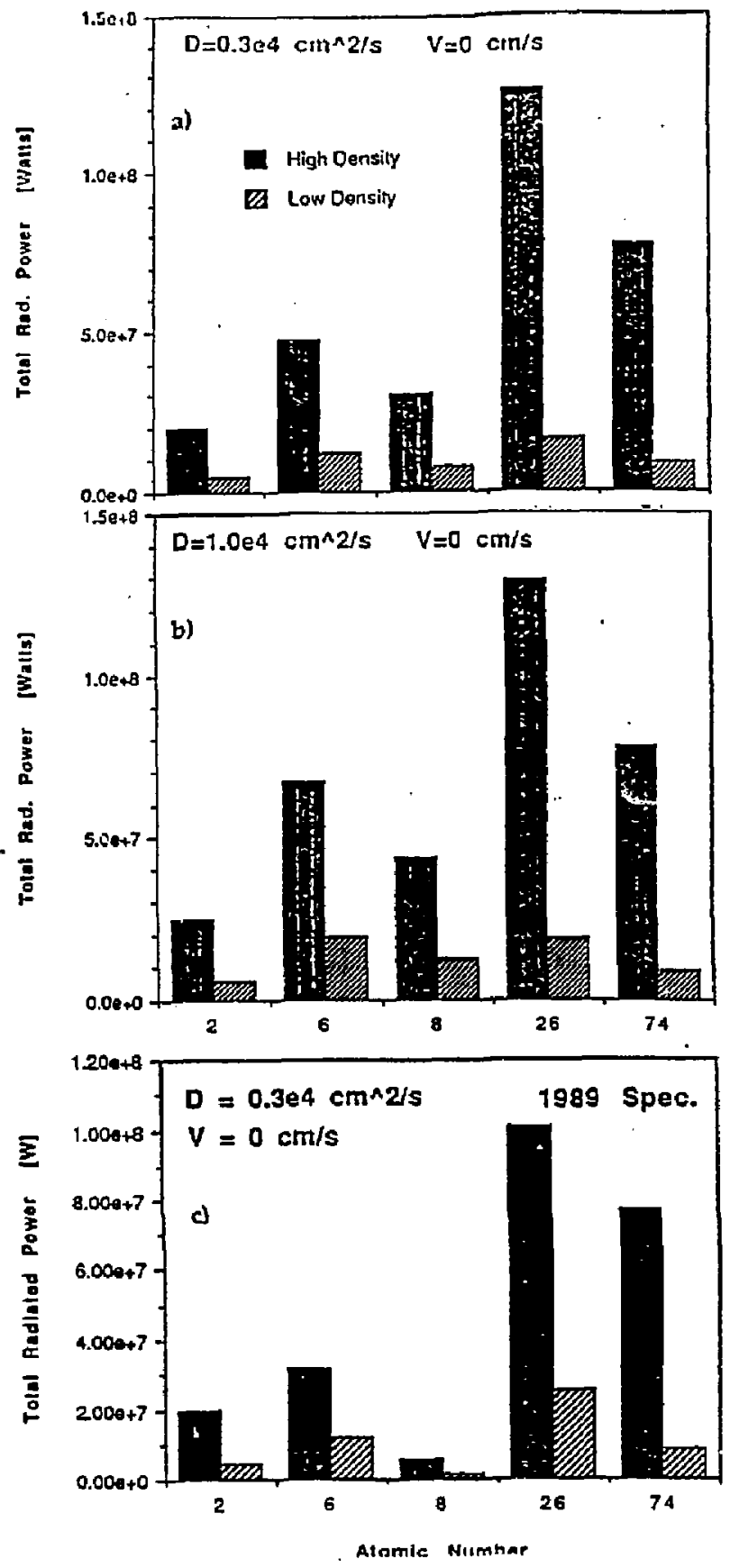

Fig. 11. Total radiated power predicted for each impurity element in ITER, based on the impurity concentrations specified: a) and b) in 1988 for two different diffusivities; c) in 1989 for a single diffusivity. 
ITER Total Impurity Radiation

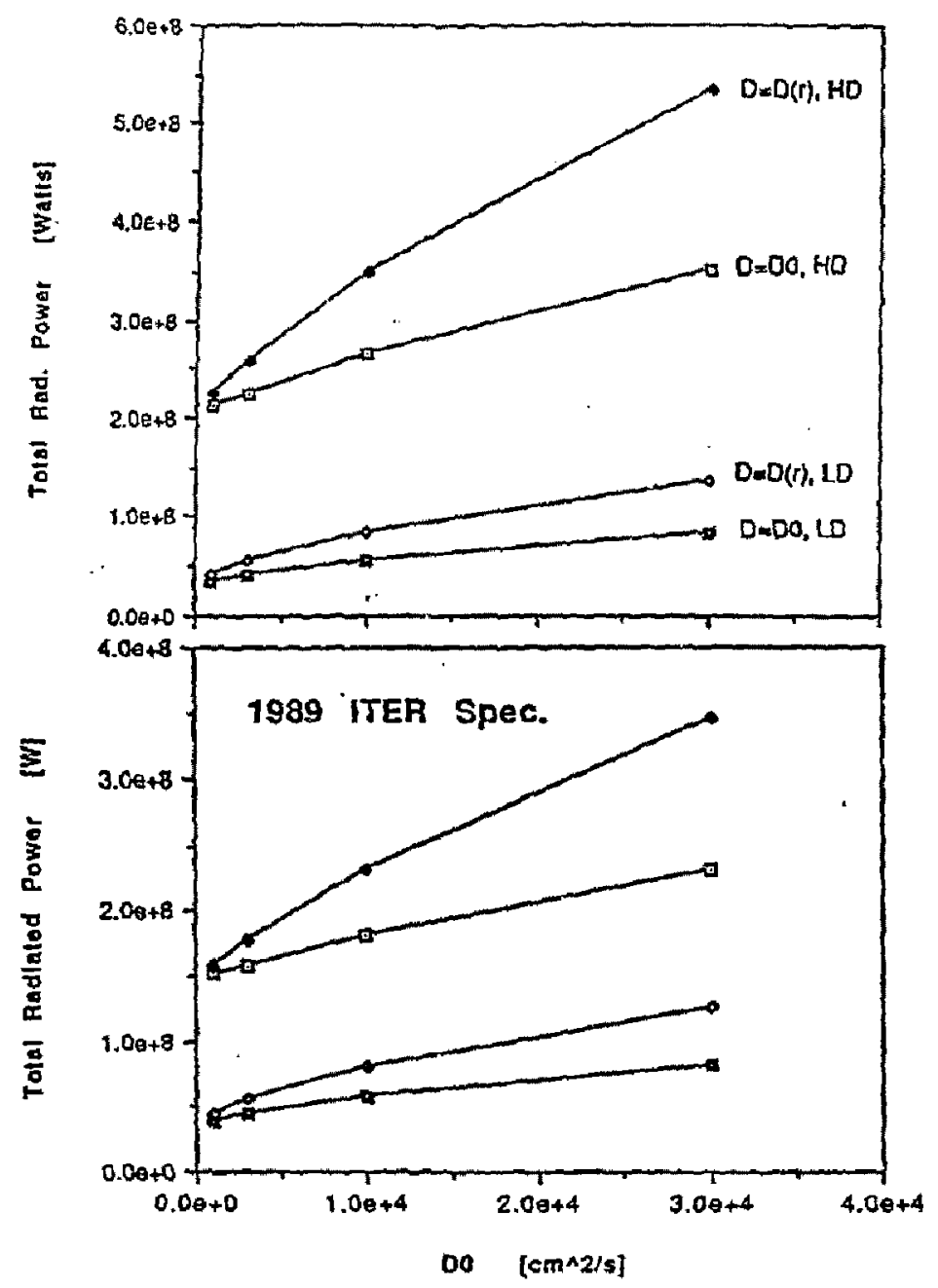
Fig. 12. Diffusivify dependence of total radiated power for ITER: a) based on 1988
impurity specification and b) based on 1989 impurity specification. 


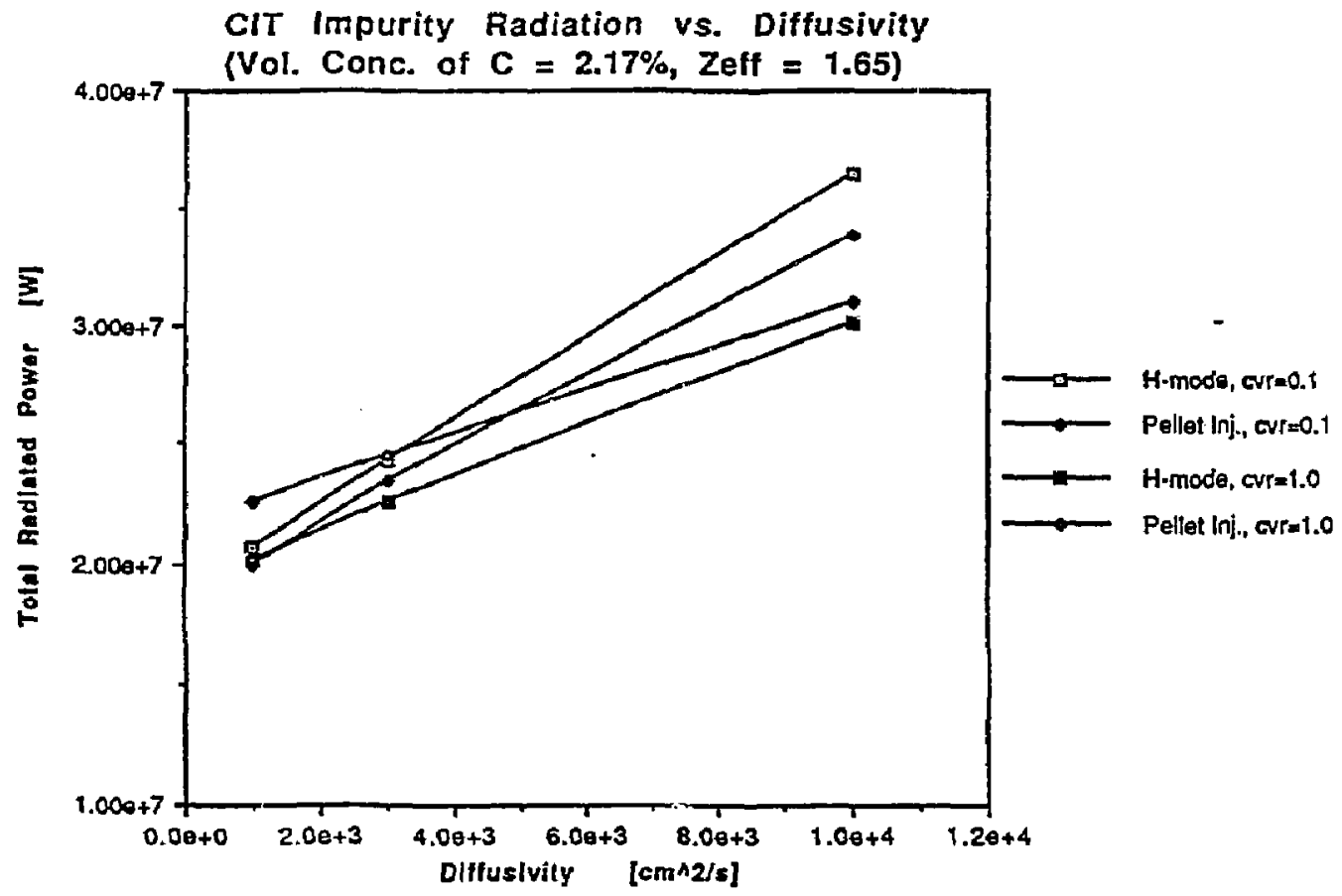

Fig. 13. Predicted total impurity radiation from CIT as a function of difusivity. 


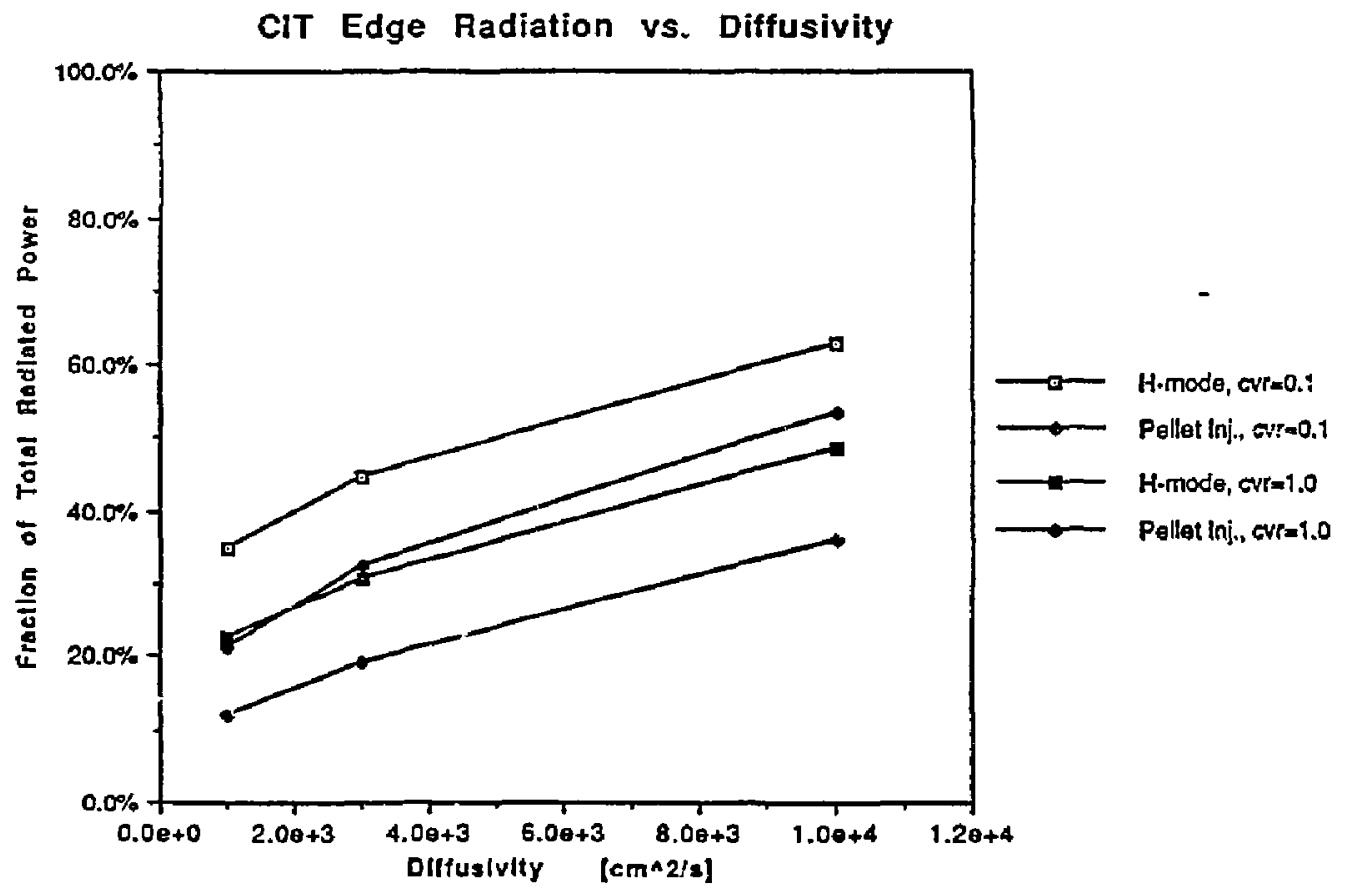

Fig. 14. Predicted edge and SOL impurity radiation from CIT as a function of diffusivity. 


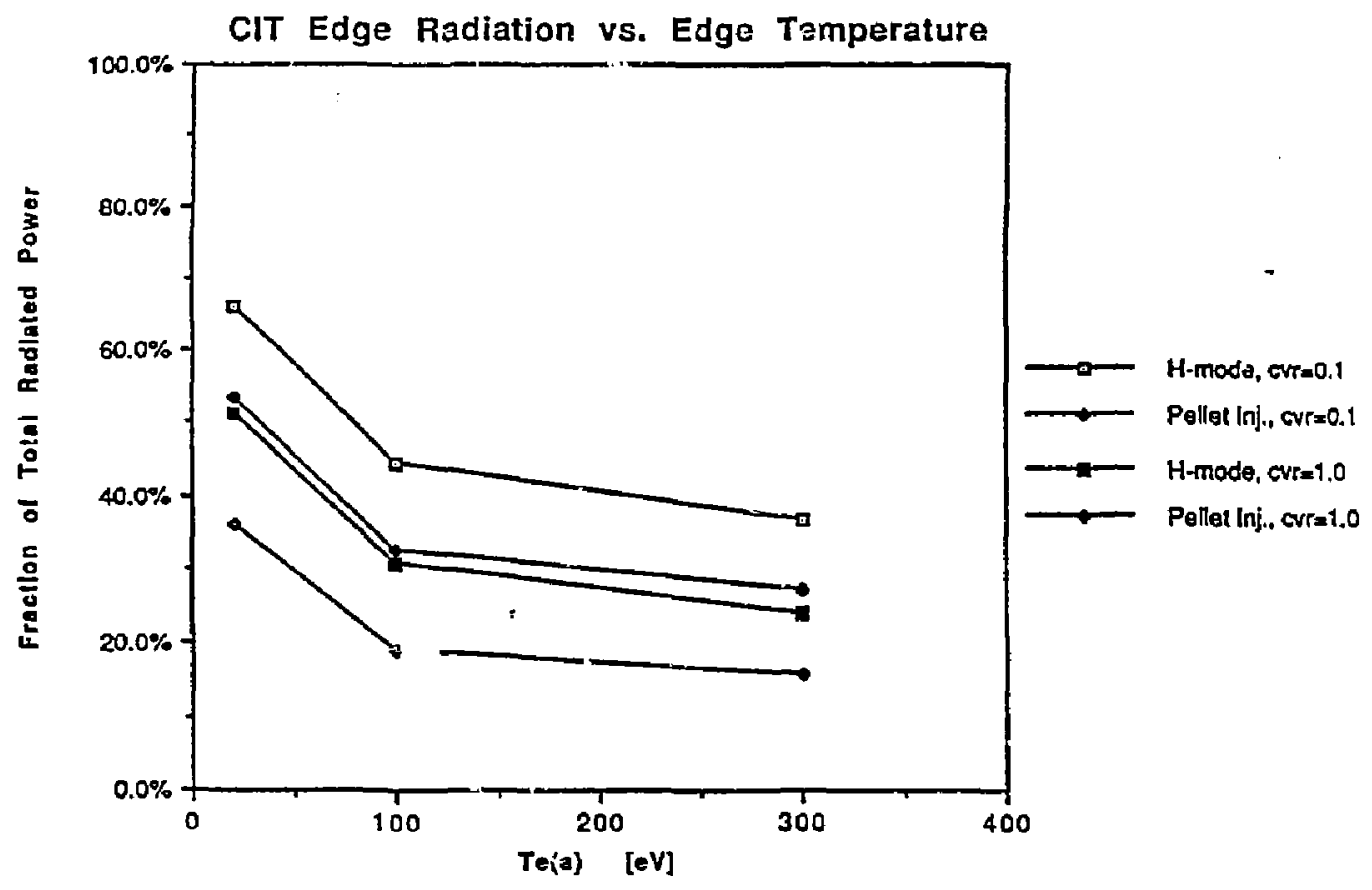

Fig. 15. Predicted edge impurity sadiation from CIT as a function of separatrix temperature. 


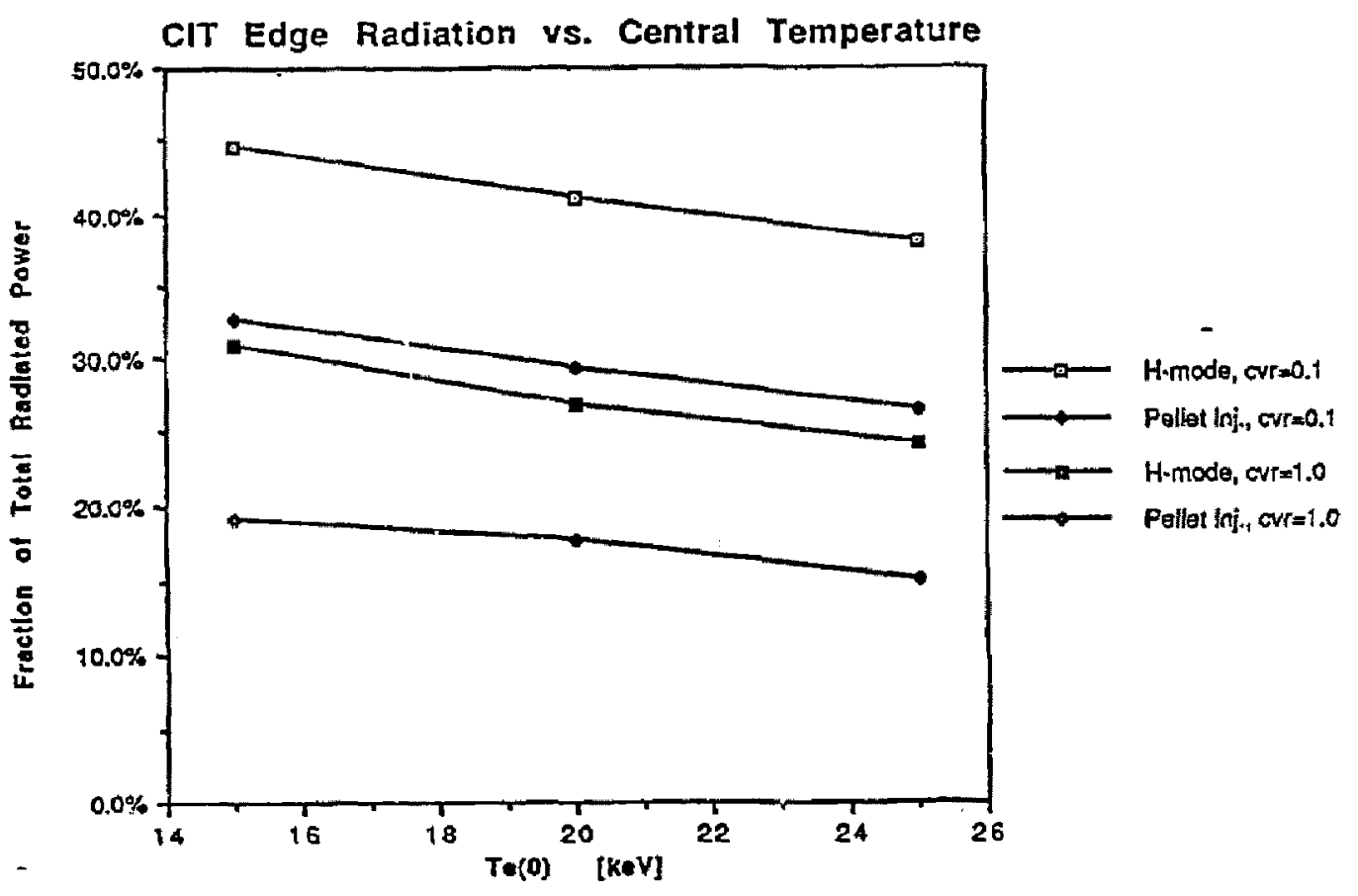

Fig. 16. Fraction of edge plus SOL radiation from CIT, as a function of central electron temperature. 